Medicare Billing, Law and Practice: Complex, Incomprehensible and Beginning to Unravel Faux, Wardle and Adams

\title{
Medicare Billing, Law and Practice: Complex, Incomprehensible and Beginning to Unravel
}

\author{
Margaret Faux, Jonathan Wardle and Jon Adams*
}

\begin{abstract}
Australia's Medicare is still widely considered one of the world's best health systems. However, continual political tinkering for 40 years has led to a medical billing and payment system that has become labyrinthine in its complexity and is more vulnerable to abuse now, from all stakeholders, than when first introduced. Continuing to make alterations to Medicare without addressing underlying structural issues, may compound Australia's health reform challenges, increase the incidence of noncompliance and expenditure and thwart necessary reforms to develop a modern, datadriven, digitally informed health system. For the medical practitioners who are required to navigate the increasing complexity and relentless change, they will remain at high risk of investigation and prosecution in what has become an anarchic operating environment that they cannot avoid, but do not understand.
\end{abstract}

Keywords: health care fraud and non-compliance; health system literacy; legal liability of medical practitioners; health Insurance

\section{INTRODUCTION}

The Nimmo report in 1969 described health insurance in Australia as "unnecessarily complex and beyond the comprehension of many", and the report became the catalyst for the introduction of Australia's first universal health coverage scheme, Medibank. ${ }^{1}$ This article suggests that Australia's current health insurance arrangements have again become so complex and incomprehensible that the system is beginning to unravel.

The authors have undertaken an extensive examination of core legal provisions of tax payer-funded medical billing arrangements under Australia's public insurer, Medicare, and to the best of our knowledge this is the first time such a comprehensive review has been undertaken. It is suggested that continual political tinkering for 40 years has created a medical billing and payment system that has become labyrinthine in its complexity and is more vulnerable to abuse now than when first introduced. Further, continuing to make alterations to Medicare without addressing underlying structural issues may compound Australia's health reform challenges, increase the incidence of non-compliance and

\footnotetext{
* Margaret Faux: PhD candidate, Faculty of Health, University of Technology, Sydney, Australia. Dr Jonathan Wardle: Senior Lecturer, Faculty of Health, University of Technology Sydney, Australia; Visiting Professor, School of Medicine, Boston University; Trans-Pacific Fellow, School of Medicine, University of Washington. Professor Jon Adams: ARC Professorial Future Fellow, Professor of Public Health, Director, ARCCIM, Faculty of Health, University of Technology, Sydney, Australia. This research received no specific grant from any funding agency in the public, commercial or not-for-profit sectors.

Competing interests statement: Margaret Faux is the founder and CEO of a medical billing company, and the holder of a patent for a medical billing app. Ms Faux's company also provides online education on the topic of medical billing for medical practitioners.

Correspondence to: margaret.a.faux@student.uts.edu.au.

1 Australia, Commonwealth Committee of Enquiry into Health Insurance, JA Nimmo, Health Insurance, Report of the Commonwealth Committee of Enquiry $\quad$ (March $<$ https://parlinfo.aph.gov.au/parlInfo/search/display/display.w3p;query=Id:\%22library/lcatalog/10134931\%22>.
} 
expenditure, thwart necessary steps to develop a modern, data-driven digitally informed health system, and risk destroying what is widely considered one of the best health systems in the world. ${ }^{2}$

\section{Historical CONTEXT}

Dr Frank Gaha was the only medical practitioner in the House of Representatives on the night of 9 April 1946. ${ }^{3}$ To him the proposal to add 11 words into the Constitutional Amendment Bill represented little more than overzealous obsession on the part of the "legal gentlemen". A few months later, on 28 September 1946, one of the most successful referendums in Australian history led to the insertion of s 51(xxiiiA) into the Australian Constitution ${ }^{4}$ including the verbiage which Gaha had thought redundant, "but not so as to authorise any form of civil conscription" (hereafter referred to as the CCC meaning civil conscription caveat). ${ }^{5}$

Far from redundant, the CCC became a foundation on which Australia's health system was built. ${ }^{6}$ The CCC prevented the full implementation of the National Health Service Acts of $1948,{ }^{7}$ directly impacted upon many of the structural choices made by the Federal Government during the implementation of Australia's original universal health insurance scheme, Medibank, ${ }^{8}$ and may be at the heart of many of the health reform challenges Australia is facing today. ${ }^{9}$

Almost 70 years later, 38 High Court judges have settled three points of law (Table 1) in relation to the interpretation of the CCC as follows:

(1) The relationship between a medical practitioner and patient is a contract, governed by general principles of contract law.

(2) Both legal and practical compulsion may offend the CCC.

(3) The CCC applies to medical and dental services only and not to other services described in $\mathrm{s}$ 51(xxiiiA).

Table 1

\begin{tabular}{|l|c|}
\hline Case Name & $\begin{array}{c}\text { No. of } \\
\text { Judges }\end{array}$ \\
\hline
\end{tabular}

${ }^{2}$ EC Schneider et al, Mirror, Mirror 2017: International Comparison Reflects Flaws and Opportunities for Better U.S. Health Care $<$ https://interactives.commonwealthfund.org/2017/july/mirror-mirror/>.

3 Commonwealth, Parliamentary Debates, House of Representatives, $9 \quad$ April 1946 $<$ https://parlinfo.aph.gov.au/parlInfo/search/display/display.w3p;adv=yes;db=HANSARD80;id=hansard80\%2Fhansardr80\%2F1 946-04-09\%2F0151;orderBy= fragment number,doc date-

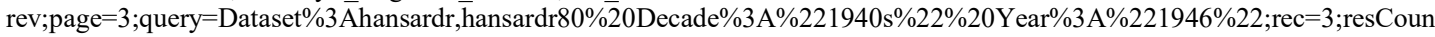
$\mathrm{t}=$ Default $>$.

${ }^{4}$ The Social Services Referendum was passed nationally and in six States making it one of Australia's most successful referendums $<$ https://www.electoralgeography.com/new/en/countries/a/australia/1946-referendum-australia.html $>$.

${ }^{5}$ An explanation by Robert Menzies, of the words "but not so as to authorize any form of civil conscription" which he successfully proposed be inserted into the Constitution can be read at this link $<$ https://parlinfo.aph.gov.au/parlInfo/search/display/display.w3p;adv=yes;db=HANSARD80;id=hansard $80 \% 2 F h a n s a r d r 80 \% 2 F 1$ 946-04-09\%2F0149; orderBy= fragment number,doc daterev;page $=3 ;$ query $=$ Dataset $\% 3 \bar{A}$ hansardr, $\bar{h}$ ansardr80\%20Decade $\% 3 \mathrm{~A} \% 221940$ s\%22\%20Year\%3A $\% 221946 \% 22 ;$ rec $=3 ;$;resCoun $\mathrm{t}=$ Default $>$.

${ }^{6}$ Medicare's enabling Legislation is the Health Insurance Act 1973 (Cth). Despite its name, it is not a law for Insurance (discussed in this article) but a law enacted pursuant to the new s 51(xxiiiA) of the Constitution, as a law for the provision of medical and dental services. From the outset, optometrical services were included.

${ }^{7}$ A-m Boxall and JA Gillespie, Making Medicare: The Politics of Universal Health Care in Australia (UNSW Press, 2013) 28, 29.

${ }^{8}$ G Whitlam, Curtin Memorial Lecture $1961<$ http://john.curtin.edu.au/jcmemlect/whitlam1961.html\#anchor1597583>.

${ }^{9}$ Australia's current out-of-pocket medical costs crisis has been attributed to the practical impact of the Constitution s 51(xxiiiA) $<$ https://insidestory.org.au/healthcares-out-of-pocket-crisis/>. 


\begin{tabular}{|l|l|}
\hline British Medical Association v Commonwealth (1949) 79 CLR 201 & 6 \\
\hline General Practitioners Society of Australia v Commonwealth 145 CLR 532 & 7 \\
\hline Alexandra Private Geriatric Hospital Pty Ltd v Commonwealth (1987) 62 CLR 271 & 5 \\
\hline \begin{tabular}{l} 
Health Insurance Commission v Peverill (1994) 179 CLR 226 \\
\hline $\begin{array}{l}\text { Breen v Williams (1996) 186 CLR 71* } \\
\text { s 51(xxiiiA) specifically }\end{array}$
\end{tabular} & 7 \\
\hline $\begin{array}{l}\text { Wong v Commonwealth (2009) 236 CLR 573; [2009] HCA 3 } \\
\text { Total }\end{array}$ & 6 \\
\hline
\end{tabular}

Historical records suggest a political preference at the time of the introduction of Medibank to socialise medicine ${ }^{10}$ but this was problematic for the government because the CCC prevented (and still prevents) the Federal Government from implementing an $\mathrm{NHS}^{11}$ style of health system in which medical practitioners can be employed as public servants. This has effectively enshrined the small business nature of Australian medical practice, enabling medical practitioners to set fees as they wish. More recently, the CCC was described by the High Court as a rare constitutional guarantee which benefits both parties equally by preserving freedom of choice for consumers, who cannot be forced to have a required relationship with a medical practitioner without their consent. ${ }^{12}$

Despite the seemingly impenetrable barrier imposed by the CCC, on 1 July 1975, the Federal Government successfully introduced Medibank (later Medicare), which provided health sector funding across two distinct domains, enabled by two separate sections of the Constitution:

(1) the provision of free public hospital services via conditional federal grants made to State and Territory Governments under s $96,{ }^{13}$ and

(2) subsidised private services rendered by medical practitioners on a fee for service basis pursuant to laws made under s 51(xxiiiA).

This structure, which endures today, has allowed the Federal Government to control State-run public hospitals indirectly and subsidise out-of-pocket costs for consumers accessing private sector services.

Today, decisions concerning the interpretation of the CCC are being felt in the health reform space, where the need to control escalating federal health expenditure sits at odds with the unique position of power and privilege held by Australian medical practitioners who have constitutional protection against excessive government intrusion into the private contractual arrangements they negotiate with their patients. In short, if available rebates (whether from the government or other payers) are perceived as insufficient by an individual medical practitioner, subject to any contractual barriers, the medical practitioner has a constitutional right to charge any amount.

\footnotetext{
${ }^{10}$ Whitlam, n 8.

${ }^{11}$ The National Health Service, known as the NHS, is the publicly funded Universal Health Coverage system in the United Kingdom. For more information visit this link <https://www.nhs.uk/>.

${ }^{12}$ Wong v Commonwealth (2009) 236 CLR 573; [2009] HCA 3.

${ }^{13}$ Whitlam, n 8.
} 
The original scheme included approximately one thousand subsidised services. ${ }^{14}$ Today there are almost six thousand, accessible by numerous providers and stakeholders beyond medical practitioners. ${ }^{15}$ However, medical practitioners remain the largest group of Medicare-eligible providers ${ }^{16}$ and most are dependent on the scheme for their livelihoods. ${ }^{17}$

In the 40 years since the scheme was introduced, the daily business of matching increasingly complex clinical encounters to the scheme's administrative dataset has become much more difficult, and understanding the scheme's requirements can sometimes be challenging. Further, despite the CCC, there are numerous circumstances in daily practice when medical practitioners cannot set their fees as they wish, and when charges cannot lawfully be raised against their patients, although they may not know this. Examples are presented in this article.

\section{The FinANCiAl ImPACT OF NON-COMPlint BILling AND FraUd}

Health expenditure in Australia and internationally is outpacing Gross Domestic Product (GDP) growth ${ }^{18}$ and the World Health Organization has stated that "Health systems haemorrhage money", ${ }^{19}$ citing 10 categories of waste, one being fraud and corruption. ${ }^{20}$ Some commentators have suggested that irrespective of system design, no health care system is safe from fraud due to inevitable regulatory gaps where inappropriate extraction of money from health funding pools can occur. ${ }^{21}$ In Australia, precise quantification of non-compliant Medicare billing has remained elusive, but one commentator has suggested deliberate misuse by medical practitioners costs taxpayers $\$ 2-3$ billion annually or $10-15 \%$ of the schemes' total cost. ${ }^{22}$

In Australia, strategies to promote medical practitioner compliance have featured heavily in departmental reports, ${ }^{23}$ the most common being education programs designed to encourage voluntary compliance. This is then augmented with post-payment audit activity. ${ }^{24}$

14 The Medical benefits Schedule Book April 1974 with amendments to February 1975 <http://www.mbsonline.gov.au/internet/mbsonline/publishing.nsf/Content/515793D58E889BD0CA257CD100033990/\$File/197 4\%20Apr\%20MBS\%20-\%20AUS.pdf>.

15 MBS Online, The 2019 Medicare Benefits $<$ http://www.mbsonline.gov.au/internet/mbsonline/publishing.nsf/Content/Downloads-201904>.

${ }^{16}$ MBS Online , $\mathrm{n} 15$.

${ }^{17}$ Wong $v$ Commonwealth (2009) 236 CLR 573; [2009] HCA 3.

18 World Health Organization, Public Spending on Health: A Closer Look at Global Trends $<$ https://www.who.int/health_financing/documents/health-expenditure-report-2018/en/>.

${ }^{19}$ World Health Organization, Health Systems Financing: The Path to Universal Coverage $<\mathrm{https}$ ://www.who.int/whr/2010/en/>.

${ }^{20}$ World Health Organization, n 19.

$21 \mathrm{~J}$ Gee et al, The Financial Cost of Healthcare Fraud, What Data from around the World Shows, http:/www2.port.ac.uk/media/contacts-and-departments/icjs/ccfs/The-Financial-Cost-of-Healthcare-Fraud-Report-2015.pdf.

${ }^{22}$ T Webber, "What Is Wrong with Medicare?" (2012) 196(1) MJA 18.

${ }^{23}$ Australian National Audit Office, The Auditor-General, Department of Human Services, Medicare Compliance Audits, Audit Report No 26 (2013-2014) <https://www.anao.gov.au/work/performance-audit/medicare-compliance-audits>.

${ }^{24}$ Australian National Audit Office, n 23. In 2008-2009 the federal government announced an "Increased Medicare Compliance Audit Initiative (IMCA)" which was designed to strengthen Medicare's audit capabilities. The IMCA provided additional funding to enable increased compliance audits from 500 to 2500 annually. The work had been expected to generate savings of $\$ 147.2$ million over four years or $\$ 36.8$ million per year. The net result was a $\$ 128.3$ million shortfall in anticipated savings. These figures provide a useful basis from which to extrapolate a governmental approximation of $\$ 1.2$ billion or approximately $6.8 \%$ of inappropriate Medicare claims annually. 
Australian popular media often refer to non-compliant Medicare billing as "overservicing" 25 or "rorting" 26 neither of which has any legal meaning or relevance. The term "overservicing" was removed from Medicare's regulatory framework in 1994, ${ }^{27}$ replaced with "inappropriate practice". ${ }^{28}$

The Medicare scheme is enabled by the Health Insurance Act 1973 (Cth) (HIA), which is a law within the scope of the Federal Governments Financial Accountability framework and therefore, in addition to offences of inappropriate practice, offences under the HIA necessarily include sanctions under the Criminal Code Act (Cth) ${ }^{29}$ where criminal fraud may be prosecuted for serious breaches of the scheme's requirements.

Both civil and criminal offences have been consistently reported since the inception of the scheme, ${ }^{30}$ and the majority of available commentary suggests that all incorrect claiming is fraudulent ${ }^{31}$ implying the perpetrator may have the necessary mens rea to act with deliberate intent to defraud. However, results of a recent study ${ }^{32}$ which found that Australian medical practitioners may not know (and have never been formally taught) how to bill correctly using Medicare, challenges this assumption.

Irrespective of whether incorrect medical billing is intentional or not, in the current context of pressured health budgets and public expectations, the financial consequences of erroneous billing under Medicare have become a problem of sufficient magnitude that the question of how and why it is occurring can no longer be ignored.

\section{CONFUSion Starts With the LANGUAge OF THE LAW}

Enforcement is only possible when concepts are clearly defined, either by the plain words and ordinary meaning of legislation or by judicial interpretation. Unfortunately, in the area of inappropriate practice and fraudulent breaches of the Medicare scheme, there is a relatively small body of case law and some key terms within the scheme are therefore important to consider, as they may themselves be possible root causes of non-compliant billing by medical practitioners.

\section{Use of the Term "Health Insurance"}

The original Medibank scheme was enabled by two Acts of Parliament: the HIA and the Health Insurance Commission Act 1973 (Cth). ${ }^{33}$ After major reforms to the Public Service sector in 2005, the Health Insurance Commission Act 1973 was superseded and is now the Human Services (Medicare) Act

\footnotetext{
25 J Medew, "Too Many Patients Receiving Unnecessary Medicine, Doctors Say”, The Age, 9 January 2017 $<$ https://www.theage.com.au/national/victoria/too-many-patients-receiving-unnecessary-medicine-doctors-say-20170109gtofmb.html>.

26 N Evans, "Medicare Watchdog Claims \$21m Back Over Medico Rorts", PerthNow, 15 November 2018 $<$ https://www.perthnow.com.au/news/public-health/medicare-watchdog-claims-21m-back-over-medico-rorts-ng-b881022056z>.

27 R Bell, Medicare Regulation through Professional Services Review - Lessons Learned $<$ https:/heinonline.org/HOL/LandingPage?handle=hein.journals/lwincntx23\&div=21\&id=\&page=>.

${ }^{28}$ Health Insurance Act 1973 (Cth) s 80.

${ }^{29}$ Health Insurance Act 1973 (Cth) s 127, penalty for breach of s 20A.

${ }^{30}$ Bell, n 27.

${ }^{31}$ Webber, n 22; K Flynn, Medical Fraud and Inappropriate Practice in Medibank and Medicare, Australia 1975-1995. Doctor of Philosophy thesis, School of Social Sciences, Media and Communications, University of Wollongong, 2004.

${ }^{32}$ M Faux et al, "Who Teaches Medical Billing? A National Cross-sectional Survey of Australian Medical Education Stakeholders (2018) 8 BMJ Open e020712.

${ }^{33}$ RB Scotton and CR Macdonald, The Making of Medibank (University of New South Wales, School of Health Services Management, 1993).
} 
1973 (Cth), ${ }^{34}$ but the HIA remains. The HIA sets out eligibility criteria, billing rules and contains mechanical provisions which facilitate the operation of the Medicare scheme.

Despite its name, the HIA is not a law for the provision of insurance. The High Court has deemed it a law for the provision of medical and dental services pursuant to s 51(xxiiiA) of the Constitution rather than a law pursuant to the insurance head of power, s 51(xiv). ${ }^{35}$ In contrast, the Private Health Insurance Act 2007 (Cth), defines "insurance" as having the meaning to which para 51(xiv) of the Constitution applies. $^{36}$

Over time, Australia has significantly expanded the original public health funding arrangements and now operates within a complex blended system of both public and private health financing. However, use of the term "insurance" to describe both public and private funding arrangements may be a subtle contributor to confusion in relation to understanding contractual obligations surrounding individual medical billing transactions. This is so because Australia's public Medicare scheme cannot properly be described as a health insurance scheme as it does not carry out insurance business, a central feature of which is the issuing of contracts. Insurance law is in essence, the law of contract, ${ }^{37}$ where a binding contract of insurance exists between relevant parties.

Consumer understanding of the term "insurance" is most relevant in areas such as motor vehicle insurance where common features of insurance contracts include; legal entitlement, uncertainty, insurable interest, voluntariness, the provision of money's worth, no control by the party assuming the risk and the carrying out of insurance business which will usually include issuing premium and policy documents. ${ }^{38}$ While not an exhaustive list, it is evident that public health financing arrangements such as Medicare typically exclude some of these components, most obviously voluntariness.

In Health Insurance Commission v Peverill (Peverill), ${ }^{39}$ the Australian High Court settled certain key issues concerning the legal nature of the Medicare benefit including when the benefit becomes payable and who has contracts with whom in the context of a Medicare billing transaction involving three parties - a patient, a provider of professional services (usually a medical practitioner) and the government.

\section{Legal Entitlement to the Medicare Benefit}

Peverill confirmed the existence of a contract between the medical practitioner and patient, ${ }^{40}$ but the $H I A^{41}$ did not give rise to a contract between the patient and the government ${ }^{42}$ nor between the medical practitioner and the government. ${ }^{43}$ The Court characterised the Medicare benefit not as a proprietary right ${ }^{44}$ but as a statutory gratuity payable to the patient, ${ }^{45}$ and a chose in action that may be acquired by the medical practitioner. ${ }^{46}$ Brennan J stated that Medicare benefits become payable immediately upon

\footnotetext{
34 Medicare Australia, Annual Report 2005-2006

$<$ https://www.humanservices.gov.au/sites/default/files/documents/medicare-annual-report-0506-complete.pdf $>$.

${ }^{35}$ Wong v Commonwealth (2009) 236 CLR 573; [2009] HCA 3.

${ }^{36}$ Private Health Insurance Act 2007 (Cth) s 5.1.

${ }^{37}$ J Birds, Birds Modern Insurance Law (Sweet \& Maxwell, $9^{\text {th }}$ ed, 2013).

${ }^{38}$ Birds, n 37, 10-12.

${ }^{39}$ Health Insurance Commission v Peverill (1994) 179 CLR 226.

${ }^{40}$ Health Insurance Commission v Peverill (1994) 179 CLR 226.

${ }^{41}$ Health Insurance Commission v Peverill (1994) 179 CLR 226.

${ }^{42}$ Health Insurance Commission v Peverill (1994) 179 CLR 226.

${ }^{43}$ Health Insurance Commission v Peverill (1994) 179 CLR 226.

${ }^{44}$ Health Insurance Commission v Peverill (1994) 179 CLR 226.

${ }^{45}$ Health Insurance Commission v Peverill (1994) 179 CLR 226.

${ }^{46}$ Health Insurance Commission v Peverill (1994) 179 CLR 226.
} 
claims being both lodged and accepted, ${ }^{47}$ but neither the patient nor the medical practitioner has a right to sue for unpaid Medicare benefits as no debt accrues to the benefit of either party. Further, payment of Medicare rebates is subject to government policy and the continuing will of the Parliament and may be altered or withdrawn any time. ${ }^{48}$

Peverill also confirmed that the patient or "eligible person" 49 is the exclusive beneficiary of Medicare benefits ${ }^{50}$ and that consent must be obtained from the eligible person before the benefit can be assigned to a provider of professional services.

Therefore, for practical purposes, while medical practitioners can charge as they wish under the contracts they enter into with their patients, they cannot obtain the patient's Medicare benefit until agreement is reached and consent given. This important inbuilt compliance mechanism is the only step in a medical billing transaction directly involving the patient. By requiring the patient's signature to evidence consent, the billing of fictitious services and patient attendances is prevented and the patient is afforded an opportunity to review services itemised on the agreement.

Provided for in s 20B, the assignor (the patient) must sign and retain a copy of the agreement, ${ }^{51}$ and $\mathrm{s}$ 127 creates a strict liability offence if a copy of the signed agreement is not given to the patient. ${ }^{52}$

However, the patient consent requirement is also anachronistic because Medicare has evolved to include many reimbursed services where the patient is not required to be physically present. ${ }^{53}$ Even when present, very few patients will today elect to retain paper copies of consent agreements, particularly as Medicare itself no longer requires practitioners to retain them either. ${ }^{54}$

By diluting the signature requirement in this way it is arguable the Commonwealth has undermined the provisions of s $20 \mathrm{~B}$ and exposed Medicare to increased vulnerability and misuse. One example is the use of Medicare to recover bad debts. There is now nothing to prevent a medical practitioner submitting an electronic bill to Medicare for an overdue private patient debt without the patient's knowledge or consent, because neither party is required to retain the consent agreement. The medical record of the medical practitioner would usually provide evidence that the service took place but will provide no information concerning whether the billing was compliant. ${ }^{55}$

A myriad of similar transaction level decisions are made every day by medical practitioners as they go about their daily work, and while current government statistics suggest high rates of bulk billing ${ }^{56}$ there is no mechanism available to test the veracity of the data because both intentional and unintentional misuse of bulk billing will usually not be visible. ${ }^{57}$

\footnotetext{
${ }^{47}$ Health Insurance Commission v Peverill (1994) 179 CLR 226.

${ }^{48}$ Health Insurance Commission v Peverill (1994) 179 CLR 226.

${ }^{49}$ Health Insurance Commission v Peverill (1994) 179 CLR 226.

${ }^{50}$ Health Insurance Commission v Peverill (1994) 179 CLR 226.

${ }^{51}$ Health Insurance Act 1973 (Cth) s 20B.

${ }^{52}$ Health Insurance Act 1973 (Cth) s 127.

${ }^{53}$ See, eg, Medicare Benefits Schedule, Case Conferences by Consultant Physician - (items 820 to 838, 6029 to 6034 and 6064 to $6075)<\mathrm{http} / /$ www9.health.gov.au/mbs/fullDisplay.cfm?type=note\&q=AN.0.51\&qt=noteID\&criteria $=$ case $\% 20$ conferences $>$.

${ }^{54}$ Department of Human Services, Assignment of benefit documents <https://www.humanservices.gov.au/organisations/healthprofessionals/services/medicare/medicare-online-health-professionals $>$.

${ }^{55}$ For example, it is illegal to obtain the patient's Medicare rebate and also charge a gap simultaneously (see the case of Sood below). But now, a patient could have paid $\$ 100$ to the medical practitioner, still owe another $\$ 100$, but because the patient has forgotten or has refused to pay the balance, the medical practitioner could simply unlawfully bill through Medicare to obtain the patient's Medicare rebate.

56 The Hon Greg Hunt MP, Minister for Health, Highest bulk-billing rate on record, $<$ http://www.health.gov.au/internet/ministers/publishing.nsf/Content/health-mediarel-yr2018-hunt024.htm>.

${ }^{57}$ For example, a medical practitioner who mistakenly believes it is lawful to bulk bill a consultation and charge a separate $\$ 20$ administration fee is unlikely to come to Medicare's attention even though the conduct is fraudulent. Medicare data will cite
} 


\section{What Is a "Medical Service?"}

During the 1946 Social Services Referendum the "YES" case put to Australians described the proposed constitutional change as applying to services provided by medical practitioners and dentists only. ${ }^{58}$ However, when Medibank was introduced almost 30 years later, a small number of optometry services were included. The optometry profession had initially proposed that their new Medibank eligible services be described as relating to "specified conditions" rather than to "medical conditions", but this was not acceded to on the basis that the correct description of all relevant subsidised services (noting the optometry services could also be provided by medically qualified ophthalmologists) under the new scheme was "medical conditions" which providers of medical services could provide. However, when the $H I A$ was introduced, medical and dental services were grouped under a new term - "professional service" - though the reasons for this decision are unclear. One suggestion is that the inclusion of the optometrical services which were approved just 10 days before the scheme commenced necessitated a rushed decision regarding the need for an overarching term. The term "professional services" continues in use today, though it follows that the very fact of including optometrists from the outset means that providers of medical and dental services, described in s 51(xxiiiA), includes (and has always included) a wider class of persons than just medical practitioners and dentists, further, that a medical service itself has a wider meaning than being a service for treatment of a medical condition that only a medical practitioner can provide. Indeed today, the Medicare scheme subsidises 28 optometry services, ${ }^{59}$ numerous services provided by a raft of allied health practitioners and nurses, ${ }^{60}$ and many of the more recently added "professional services" are services that neither medical practitioners nor dentists have the training or skills to provide, such as exercise physiology, physiotherapy, chiropractic and dietetics services.

\section{What Is a "Professional Service?"}

Section 3 of the HIA defines "professional service" as being a "clinically relevant service" and the subsequent definition of "clinically relevant service" includes necessity as an element.

Interpretation of what constitutes a clinically relevant and necessary professional service is framed broadly to facilitate the art of medicine, ${ }^{61}$ ensuring medical practitioners are free to exercise appropriate clinical discretion on a case-by-case basis. This approach also aligns with a guiding principle described in the Health Practitioner National Law to enable innovation in service delivery. ${ }^{62}$ However, there may be a disconnect between the clinical skill set of medical practitioners and the administrative approach of Medicare, the ubiquitous effects of which permeate millions of decisions every day, ultimately impacting the corresponding billing transactions and health system spending. For medical practitioners, daily clinical decisions concerning whether a test or treatment is both clinically relevant and necessary will depend on numerous factors that may be poorly aligned with Medicare's approach, including nonclinical factors such as a perceived risk of subsequent litigation. ${ }^{63}$

evidence of an electronic bulk billed service, which on its own would not trigger alerts of impropriety. Patients are also unlikely to complain in such circumstances because by bulk billing, the medical practitioner has reduced their out of pocket expenses, only requiring nominal payments which most would assume to be legal.

${ }^{58}$ Wong $v$ Commonwealth (2009) 236 CLR 573; [2009] HCA 3 (Kirby J).

59 Medicare $\quad$ Benefits Schedule Category 1 , Group $\quad$ A10 $<$ http://www.mbsonline.gov.au/internet/mbsonline/publishing.nsf/Content/downloads $>$.

${ }^{60}$ Medicare Benefits Schedule, Category 8 services, $\mathrm{n} 59$.

${ }^{61}$ The most famous author on the topic of the art of medicine was Sir William Osler, who was famously quoted as saying "The practice of medicine is an art not a trade: a calling, not a business: a calling in which your heart will be exercised equally with your head": see <https://www.azquotes.com/author/11160-William_Osler>. The underlying principle posits that medical practitioners are guided by science, but treat patients as individuals.

${ }^{62}$ Health Practitioner Regulation National Law Act 2009 (Qld) s 2(f).

${ }^{63}$ For example - in the circumstances of a 50-y-o woman presenting with a two-day history of painful urination and fevers, and a past history of having had a kidney infection five years ago, it would be both clinically relevant and necessary to take a urine 
The government has no ability to determine clinical relevance or necessity because it has no visibility over the reason why a patient attended a medical practitioner in the first place. Billing through Medicare requires the allocation of service codes only, which do not provide diagnostic information or describe presenting symptoms. This sits at odds with processes in some other countries where international disease codes are used at the start of the medical billing process to determine why the patient presented for medical treatment, which in turn provides necessary transparency for payers regarding the relevance and necessity of services rendered. ${ }^{64}$

In addition, a lack of clarity around the parameters of what is included in a professional service has caused disagreement at the highest levels of the Australian judiciary where in one case (discussed below) the Court did not reach consensus and the resulting judgment left open the question of where a professional service begins and ends. ${ }^{65}$ This can be traced to the origins of the Medicare Benefits Schedule under which fees for professional services have always been arbitrarily allocated and do not relate to any formula or measure of work value where inclusions such as time taken, practice costs, consumables, cognitive and technical skill, physical effort and complexity might be defined. A largescale project seeking to address this important structural shortcoming was finalised by the Department of Health in $2000,{ }^{66}$ however its recommendations were never implemented.

\section{A Notable Case}

The case of Sood $v$ The Queen (Sood) demonstrates the potentially adverse impact that can follow when a medical practitioner is confused about the ambit of professional services and how to bill them correctly.

Dr Sood was a medical practitioner who was found guilty in an original jury trial of 96 counts of Medicare fraud for billing to Medicare and simultaneously charging additional fees. ${ }^{67}$ On appeal the Court considered the meaning of three words in s 20A of the HIA - "in respect of" - and did not agree on the threshold issue of what came within the ambit of the professional service in that case. ${ }^{68}$

Section 20A of the HIA provides that once an agreement between the medical practitioner and patient to direct bill has been made, the government rebate constitutes "full payment" for whatever comes within

sample for pathology testing. However while not strictly necessary because the symptoms are most likely caused by a urinary tract infection (UTI) easily treated with antibiotics, the history would make it clinically relevant to also order a kidney scan as these symptoms are also consistent with a more serious kidney infection. It would not be clinically relevant to order a brain scan. However, the decision of whether or not to order the kidney scan and its relevance may ultimately depend on hindsight, because if the correct diagnosis was a simple UTI then arguably a scan was irrelevant and unnecessary. However, if the patient was admitted to hospital that night with a serious kidney infection and a kidney scan had not been undertaken, the medical practitioner may be negligent.

${ }^{64}$ In Australia, a patient who presents to a medical practitioner with a sprained ankle, could have an ECG and an asthma management plan billed, neither of which may be clinically relevant or necessary. In the United States, for example, the medical billing process commences with the allocation of an internationally recognised disease code prior to allocating billing codes. This enables the collection of data to determine clinical relevance but also acts as a barrier to the billing of codes which do not match an appropriate disease code. So in the above example, a sprained ankle presentation may be blocked from billing an ECG and asthma plan.

${ }^{65}$ In Sood v The Queen (2006) 201 FLR 119; [2006] NSWCCA 114, Dr Sood charged separate fees for counselling patients and for operating theatre costs, at the same time as billing directly to Medicare. The Court found that the separate charges were illegal on the basis that counselling and operating theatre fees were included in the scope of the services Dr Sood had billed to Medicare. Dr Sood was found to have effectively double dipped, which was a crime.

${ }^{66}$ The Department of Health, The Relative Value Study <http://www.health.gov.au/internet/main/publishing.nsf/Content/healthrvs-overview.htm>.

${ }^{67}$ Sood v The Queen (2006) 201 FLR 119; [2006] NSWCCA 114. Dr Sood adopted a pattern of practice whereby she routinely bulk billed and charged a gap at the same time. While she held that she was charging the gap for a separate service, the prosecution successfully argued the gap was part of the service that she bulk billed, which was a criminal offence.

${ }^{68}$ The appeal was ultimately allowed on the basis of misdirection of the jury by the court of first instance, but there was no consensus on this particular issue. 
the parameters of the professional service provided ${ }^{69}$ This would therefore preclude Dr Sood from charging additional fees.

In the jury trial, counsel for Dr Sood argued that the additional fees Dr Sood charged (which she had described on the relevant invoices as "counselling and theatre fees"), were not fees in respect of the procedure she performed, but were instead fees in respect of separate professional services for which she was entitled to charge a fee. Dr Sood contended that there were up to four distinct services which might be provided to patients who attended her clinic each day: a consultation, counselling, theatre fees and a procedure. Having read the Medicare Benefits Schedule or MBS (discussed below), Dr Sood argued that she believed she was entitled to apply mixed billing arrangements across the four components, sometimes exercising her constitutional right to charge as she chose, and other times relinquishing it. This approach was (and remains) consistent with advice available for medical practitioners on Medicare's website. ${ }^{70}$

Section 20A of the HIA uses the singular "service" as opposed to the plural "services" in recognition of each Medicare service being unique and finite. Implicit in this construct is the ability for practitioners who provide more than one professional service to the same patient on the same day, to bill for those services using mixed billing arrangements, subject to certain exceptions. ${ }^{71}$

In Sood only one of the services the practitioner provided to each patient was subject to an exception and therefore it appeared open to her to direct bill the procedure, charge a private fee for the counselling and theatre fees and direct bill the consultation, as long as she accepted the government rebate "in full payment" for the relevant direct billed services. However, the Crown contended that the manual billing method used by Dr Sood included a declaration that no payments had been sought in respect of the professional services she had direct billed. By charging additional counselling and theatre fees, the Crown successfully argued that Dr Sood had sought unlawful additional payments in respect of the direct billed procedure. This was enough for a jury to return a guilty verdict to 96 counts of dishonestly obtaining a financial benefit by deception contrary to s 134.2 of the Criminal Code Act 1995 (Cth).

The Sood decision highlights the complexities in what is widely considered a simple direct bill transaction, which most Australians know and refer to as "bulk billing". Numerous aspects of the decisions both at first instance and on appeal are troubling.

At the time of the jury trial, the costs of running operating theatres, which Dr Sood described as "theatre fees" had already been separated from medical practitioner fees in Australia for a decade. ${ }^{72}$ Therefore if Dr Sood had provided the same service in a private hospital rather than in a private clinic, there would have been no ability for the prosecution to mount its argument on this point because operating theatre fees were always billed separately by the facility. ${ }^{73}$ Furthermore, the language of the service description which Dr Sood was found to have breached, made (and still makes) no mention of operating theatre costs as forming a component of the total rebate of $\$ 144.35 .^{74}$ The service description was this short phrase: "Evacuation of the contents of the gravid uterus by curettage or suction curettage." The authors

\footnotetext{
${ }^{69}$ Health Insurance Act 1973 (Cth) s 20A

${ }^{70}$ Australian Government Department of Human Services, Bulk bill payments to health professionals: Bulk billing and private billing together (Department of Human Services, 2019) <https://www.humanservices.gov.au/organisations/healthprofessionals/subjects/bulk-bill-payments-health-professionals\#a4>.

${ }^{71}$ Health Insurance Act 1973 (Cth) s 15.

72 L McDonald, 'Healthcare Funding from a Private Hospital Perspective' (2012) 2(2) HIM-INTERCHANGE 8 $<$ http://www.himaa2.org.au/HIM-I/sites/default/files/HIM-I\%202-2\%20Report\%20McDonald.pdf $>$.

${ }^{73}$ Accommodation and operating theatre fees are separately invoiced by Australian hospitals for payment either under activitybased funding arrangements or by Private Health Insurers. Medical practitioners are entitled to the medical services described only in the MBS.

${ }^{74}$ The relevant description of the procedure which Dr Sood billed was "Item 35643 Evacuation of the contents of the gravid uterus by curettage or suction curettage not being a service to which Items 35639 or 35640 applies, including procedures to which Items $35626,35627$ or 35630 applies, where performed (Anaes. $17705=3 \mathrm{~B}+2 \mathrm{~T})$ ".
} 
suggest that both the court of first instance and appeal adopted an unsatisfactorily broad interpretation of this service and went so far as to suggest that counselling also formed part of the surgical procedure. This was even though it was accepted that some patients did not go ahead with the procedure after having had and paid for a separate counselling service. ${ }^{75}$

Dr Sood repeatedly stated during the jury trial that she did not know the conduct for which she stood accused was wrong. A recent study suggests there may have been some veracity to this stance because recent evidence suggests medical practitioners do not have the high levels of legal literacy expected of them in relation to Medicare billing. ${ }^{76}$

This notwithstanding, the Commonwealth was successful in prosecuting Dr Sood and has since leveraged from this and similar decisions ${ }^{77}$ by publishing a non-exhaustive list of what it considers to be included in the scope of a professional service. However, the Sood decision may in fact have weakened the government's ability to manage compliance by shrouding every MBS item number in an infinite array of possible inclusions which will only be known to medical practitioners who find themselves before a court. ${ }^{78}$

The appeal judgment of Adams J, who dissented strongly on this point, commented that there appeared to be no satisfactory interpretation of the scheme available and expressed his view on the issue of professional service parameters in the following terms:

the Chief Justice is right to draw attention to the ubiquity in the Act of the phrase "in respect of a professional service". However, in each case the phrase could have substituted for it the word "for" without any loss of syntactical correctness. Is there a loss of referential meaning? The answer would be "yes" only if the underlying assumption is that more was intended to be covered than would be covered by the word "for". Aside from the phrase itself, the Act does not, in my respectful view, suggest the need for wider reference. The difficulty in accepting that the phrase itself is intended to reflect a wider reference is that it entails considerable uncertainty in a context where precision of scope is of considerable importance. ...The striking characteristic of the Table ... is the clinical and minute precision in which each service ... is described. ... Although the Regulations comprise a distinct statutory instrument, it forms part of a detailed, comprehensive scheme ... the acceptance of the Crown submission would, in effect, surround each item with a penumbra of indeterminate meaning inconsistent with the structure of the legislative scheme and unfair to the medical practitioners attempting to work within its boundaries.... I do not accept that the legislature intended to place doctors in the position where a not unreasonable interpretation of the Act leads them to make a claim which ex post facto a judge (or, for that matter, a jury) will find to be wrong and render them liable to criminal prosecution. ... The question of interpretation is debatable and the fact that a doctor makes a claim, even if he or she thinks it might not be justifiable ... should not render him or her liable to prosecution. ${ }^{79}$

It is noteworthy that while the majority of items and services listed in the Medicare scheme relate to specialist services, most discussion around fraudulent and non-compliant billing, as well as the majority of prosecutions, have focused on general practitioners, such as Dr Sood.

\section{The Medicare Benefits Schedule}

To assist in understanding appropriate billing practices for professional services, Australian medical practitioners are referred to a resource known as the MBS, which utilises a schedule of fees originally

\footnotetext{
${ }^{75}$ Sood v The Queen (2006) 201 FLR 119; [2006] NSWCCA 114.

${ }^{76}$ Faux et al, n 32.

${ }^{77}$ Dalima Pty Ltd v Commonwealth of Australia (Unreported, NSWSL, No 25304/87, 22 October 1987).

${ }^{78}$ Faux et al, n 32.

${ }^{79}$ Sood v The Queen (2006) 201 FLR 119, [149]-[152]; [2006] NSWCCA 114.
} 
developed in consultation with the Australian Medical Association (AMA) on a recommendation made in the Nimmo report. ${ }^{80}$

The MBS can best be described as a departmental compilation of the HIA, Regulations ${ }^{81}$ and Tables. ${ }^{82}$ However, it is not an instrument of Parliament and therefore does not have the force of law. Accordingly, interpretation of item descriptions, explanatory notes and commentary throughout the MBS is not correct statements of the law but rather interpretations as to how the government views the law, which are open to legal challenge. In the case of Sood just discussed, Dr Sood gave evidence that she had read the relevant sections of the MBS but its contents were insufficient to enable her to predict how three judges would later view the corresponding section of the legislation.

Indeed, it is common for interpretative statements contained in the MBS book to be inconsistent with the law beneath, with itself via the online version of the MBS, with the department's own online billing portal ECLIPSE (which every medical practice in the country is required to use) and with the linked funding systems that administer Australian hospital payment arrangements. Examples are described in Table 2.

Table 2

\begin{tabular}{|c|c|c|}
\hline $\begin{array}{c}\text { Brief } \\
\text { Description of } \\
\text { Issue }\end{array}$ & Details of the Discrepancy & $\begin{array}{l}\text { Impact on Medical } \\
\text { Practitioner (MP) }\end{array}$ \\
\hline $\begin{array}{l}\text { MBS book } \\
\text { inconsistent } \\
\text { with MBS } \\
\text { online version }\end{array}$ & $\begin{array}{l}\text { The MBS book states in TN.8.2 that the multiple operation rule } \\
\text { applies to all items in T8 group, except items from subgroup } 12 \text {. } \\
\text { This would include item } 44359 \text {. However, the MBS online } \\
\text { version at http://www.mbsonline.gov.au version contradicts the } \\
\text { MBS book by stating that the multiple operation rule applies to } \\
\text { item } 44359 \text {, which is confirmed as being part of T8 and } \\
\text { subgroup } 12 \text {. Section 15(4) of the HIA confirms the position } \\
\text { taken in the MBS book but not the online version, the latter of } \\
\text { which appears to be legally incorrect. }\end{array}$ & $\begin{array}{l}\text { Reliance on MBS } \\
\text { online will lead to } \\
\text { underbilling for item } \\
\text { 44359, if billing with } \\
\text { other surgical services } \\
\text { (which is usual). If } \\
\text { Medicare applies the } \\
\text { law correctly it will pay } \\
\text { higher than the amount } \\
\text { billed. This may put the } \\
\text { MP in the position of } \\
\text { believing an } \\
\text { overpayment has } \\
\text { occurred and the MP } \\
\text { may be accused of } \\
\text { rorting by not actioning } \\
\text { a refund. Conversely, if } \\
\text { Medicare applies the } \\
\text { MBS online version, the } \\
\text { MP may be accused of } \\
\text { overcharging. }\end{array}$ \\
\hline $\begin{array}{l}\text { MBS online } \\
\text { version is } \\
\text { inconsistent } \\
\text { with itself }\end{array}$ & $\begin{array}{l}\text { The description of item } 24 \text { on MBS online } \\
\mathrm{http} / / \text { www.mbsonline.gov.au implies the same fees are payable } \\
\text { for each patient seen by a GP doing a ward round in a hospital, } \\
\text { but in fact, when one clicks through to the ready reckoner it is }\end{array}$ & $\begin{array}{l}\text { MP may be accused of } \\
\text { overcharging and } \\
\text { rorting when the MP } \\
\text { was in fact making a }\end{array}$ \\
\hline
\end{tabular}

\footnotetext{
${ }^{80}$ Australia, Commonwealth Committee of Enquiry into Health Insurance, JA Nimmo, n 1. Following the Nimmo Report, the federal assembly of the AMA passed a resolution in 1969 supporting the development of a list of the "most common fees" to guide the determination of medical benefits and the subsequent list became the basis of the first MBS in 1975, which has continued to evolve for 40 years.

${ }^{81}$ Health Insurance Regulations 2018 (Cth).

${ }^{82}$ Health Insurance (General Medical Services Table) Regulations 2018 (Cth); Health Insurance (Pathology Services Table) Regulations 2018 (Cth); Health Insurance (Diagnostic Imaging Services Table) Regulations 2018 (Cth).
} 


\begin{tabular}{|c|c|c|}
\hline & $\begin{array}{l}\text { apparent this is incorrect and a sliding scale applies, meaning } \\
\text { the MP should not charge the same fee for each patient. Both } \\
\text { sections of MBS online refer to the fee being the fee for item } 23 \\
\text { plus another amount. However, this is potentially misleading } \\
\text { because item } 23 \text { is paid at } 100 \% \text { of the Medicare Schedule Fee, } \\
\text { whereas item } 24 \text { is paid at the lower inpatient rate of } 75 \% \text {. }\end{array}$ & $\begin{array}{l}\text { legitimate attempt to } \\
\text { apply the convoluted } \\
\text { and incomprehensible } \\
\text { description provided on } \\
\text { MBS online relating to } \\
\text { legitimate services } \\
\text { properly provided by } \\
\text { the MP. The MP may } \\
\text { be accused of } \\
\text { attempting to rort the } \\
\text { system if the claim } \\
\text { finally submitted is } \\
\text { incorrect. }\end{array}$ \\
\hline $\begin{array}{l}\text { Advice and } \\
\text { information } \\
\text { from } \\
\text { government is } \\
\text { inconsistent } \\
\text { with the law } \\
\text { and cannot be } \\
\text { practically } \\
\text { applied by MPs } \\
\text { due to } \\
\text { shortcomings } \\
\text { of ECLIPSE } \\
\text { online claiming } \\
\text { platform }\end{array}$ & $\begin{array}{l}\text { The MBS book states that an MP can either provide their } \\
\text { provider number on each claim, or their name and the address } \\
\text { where they provided the service. However, Medicare's online } \\
\text { help page at this link } \\
\text { https://www.humanservices.gov.au/organisations/health- } \\
\text { professionals/services/medicare/hpos/resources/managing- } \\
\text { provider-numbers implies this is not the case. It states MPs must } \\
\text { have a provider number for each location where they work. } \\
\text { However, in circumstances where Medicare refuses to issue an } \\
\text { MP with a provider number the law provides than an MP can } \\
\text { still claim by instead using their name and the address where the } \\
\text { service was provided. This is provided in Div } 5 \text { of the Health } \\
\text { Insurance Regulations Reg } 51(2) \text { (a) which provides that MPs } \\
\text { can satisfy "prescribed particular" requirements by including } \\
\text { their name and the address of the place where the service was } \\
\text { provided, in lieu of a provider number. }\end{array}$ & $\begin{array}{l}\text { However, irrespective } \\
\text { of the legal requirement } \\
\text { clearly articulated in } \\
\text { Reg } 51(2)(a) \text {, the } \\
\text { government's online } \\
\text { ECLIPSE platform } \\
\text { which all MPs are } \\
\text { required to use to } \\
\text { submit electronic } \\
\text { claims, does not include } \\
\text { a data field for an } \\
\text { address. Therefore, } \\
\text { even if an MP wanted to } \\
\text { submit a compliant } \\
\text { electronic claim to } \\
\text { Medicare using their } \\
\text { name and the address } \\
\text { where they provided the } \\
\text { service, they are } \\
\text { physically prevented } \\
\text { from doing so. This } \\
\text { may place an MP in the } \\
\text { position of being unable } \\
\text { to comply with legal } \\
\text { requirements, for which } \\
\text { the MP may be } \\
\text { investigated and } \\
\text { accused of deliberately } \\
\text { attempting to rort the } \\
\text { system. }\end{array}$ \\
\hline $\begin{array}{l}\text { MBS billing } \\
\text { codes are } \\
\text { inconsistent } \\
\text { with the } \\
\text { procedure } \\
\text { codes used to } \\
\text { reimburse } \\
\text { Australian } \\
\text { hospitals }\end{array}$ & $\begin{array}{l}\text { The procedure codes used to reimburse Australian hospitals are } \\
\text { known as ACHIs, or the Australian Classification of Health } \\
\text { Interventions. ACHIs were originally derived from the MBS. } \\
\text { There are now } 6224 \text { ACHIs which map to only } 1363 \text { MBS } \\
\text { codes, meaning the MBS and ACHIs are no longer directly } \\
\text { aligned or consistent, which can cause downstream problems for } \\
\text { MPs. For example, an MP ophthalmologist performs a cataract } \\
\text { operation and claims item } 42702 \text { which covers both the lens } \\
\text { extraction and the insertion of the new intraocular lens. The }\end{array}$ & $\begin{array}{l}\text { The MP is forced to } \\
\text { change and bill two } \\
\text { item numbers instead of } \\
\text { one, costing Australian } \\
\text { tax payers significantly } \\
\text { more. The MP may be } \\
\text { accused of rorting as a } \\
\text { result of billing two } \\
\text { services when one }\end{array}$ \\
\hline
\end{tabular}




\begin{tabular}{|c|c|c|}
\hline & $\begin{array}{l}\text { claim is rejected because it is inconsistent with the claim } \\
\text { submitted by the hospital. The hospital biller has changed the } \\
\text { MPs item numbers from } 42702 \text { to } 42701 \text { (insertion of new lens) } \\
\text { and } 42698 \text { (extraction of old lens) because item } 42702 \text { was } \\
\text { removed from the ACHIs but not from the MBS. The hospital } \\
\text { biller is therefore forced to change the MPs item numbers to } \\
\text { generate the required bill from the hospital. }\end{array}$ & $\begin{array}{l}\text { service, item } 42702, \\
\text { was clearly appropriate } \\
\text { in the circumstances. } \\
\text { The MP has effectively } \\
\text { been placed in a } \\
\text { position of having no } \\
\text { option other than to } \\
\text { double code, because } \\
\text { until she does, neither } \\
\text { her claim nor the } \\
\text { hospital's will be paid. } \\
\text { Despite the MP being } \\
\text { legally responsible for } \\
\text { the MBS services } \\
\text { claimed, a third party } \\
\text { far downstream from } \\
\text { the MP has changed the } \\
\text { MPs item numbers } \\
\text { without the MPs } \\
\text { knowledge or consent, } \\
\text { unknowingly potentially } \\
\text { exposing the MP to } \\
\text { criminal liability. }\end{array}$ \\
\hline
\end{tabular}

\section{Daily Medicare Billing from the Medical Practitioner Perspective}

Medical practitioners have no option but to engage with the Medicare scheme and comply with its requirements despite the fact that there is limited guidance as to how the scheme works, and how to bill correctly. ${ }^{83}$ So convoluted has the scheme now become, that even threshold decisions create avenues for unintentional non-compliant billing to occur.

\section{Provider Numbers and the Impact of Electronic Billing on Compliance}

Medical practitioners are required to bill using personal identifiers called "provider numbers", which are central to the integrity of the Medicare scheme. Collection of provider number data ensures the Health Department is able to track the identity of providers of professional services, analyse service delivery patterns and monitor compliance. ${ }^{84}$ However, the law pertaining to provider numbers, though recently revised, has failed to accommodate the realities of electronic billing - now the main form of bill submission - which was introduced in 2002.

Section 19(6) of the HIA requires prescribed particulars to be included on accounts and the newly revised 2018 Regulations describe those particulars as including the practitioner's name and practice address, or the practitioner's provider number. ${ }^{85}$ In similar fashion to the definitions already described, the wording of the provider number definition adds further ambiguity to claiming hurdles which medical practitioners must navigate. The regulations state that a provider number "identifies the person and a place where the

\footnotetext{
${ }^{83}$ Faux et al, n 32 .

${ }^{84}$ Department of Human Services, About Medicare Provider Numbers <https://www.humanservices.gov.au/organisations/healthprofessionals/services/medicare/medicare-benefits-health-professionals/apply-medicare-provider-number/about-medicareprovider-numbers $>$.

${ }^{85}$ Health Insurance Regulations 2018 (Cth), reg 51.
} 
person practices the person's profession", ${ }^{86}$ it does not state that a provider number identifies the person and the place where the service was provided, though this is the advise Medicare provides to medical practitioners, despite it often not being possible. ${ }^{87}$

The government facilitates electronic billing through its portal known as ECLIPSE, ${ }^{88}$ which all medical practitioners are required to use. However, many of the shortcomings of this portal exacerbate billing challenges for medical practitioners. ECLIPSE only facilitates a provider number being linked to one software system and one bank account at a time despite this being misaligned with modern medical billing, where medical practitioners may be forced to bill from multiple different software systems at a single street address ${ }^{89}$ Currently, the only way to manage this scenario is to bill using multiple provider numbers for services provided at one address, which, applying Medicare's interpretation of the Regulations, would potentially represent a breach of the scheme's requirements. However, any judicial determination would likely be focussed on whether the information provided to Medicare was false in a material particular ${ }^{90}$. The authors suggest this would be difficult to prove if a bill were otherwise correct. ${ }^{91}$

This notwithstanding, with no decided cases to assist, interpretations of the relevant regulations are speculative, including those of the government, which has itself acted inconsistently on this issue by sometimes arbitrarily allowing some medical practitioners to have two provider numbers at the same address and others not, and allowing the use of an existing provider number at an unrelated location on a temporary basis. ${ }^{92}$

The underlying provider number problem is that in the 40 years since the scheme began, a service location can now realistically be in a car with a laptop or mobile phone. ${ }^{93}$ However, the system remains designed for an era in which electronic services were not available. Failure to adapt the system to modern medical practice may therefore be encouraging unavoidable non-compliance by medical practitioners, but may have also rendered the Government unable to take any action when legitimate concerns about incorrect use of provider numbers do arise.

\section{Contracting Out of the Civil Conscription Caveat}

\footnotetext{
${ }^{86}$ Health Insurance Regulations 2018 (Cth), reg 4.

87 Department of Human Services, eLearning Modules, What Is a Provider Number? Slide 8 of 19 $<$ http://medicareaust.com/MODULES/MBS/MBSM11/index.html $>$.

${ }^{88}$ Department of Human Services, Simplified Billing and ECLIPSE < https://www.humanservices.gov.au/organisations/healthprofessionals/services/medicare/simplified-billing-and-eclipse>.

${ }^{89}$ A common example occurs when a medical practitioner has one provider number linked to Hospital A's address, but the hospital has co-located public and private hospitals and specialist consulting suites, all of which share the same street address. The medical practitioner can only have one provider number at that street address according to Medicare's current approach. However, the specialist suites may require that the medical practitioner bills through their software, the public hospital through theirs and the private hospital through a third software suite, with the revenue generated being legitimately directed into different bank accounts based on contractual arrangements. If Medicare refuses to issue additional provider numbers for the medical practitioner at the one street address, the only option is for the medical practitioner to use a different provider number for each of the three medical billing software suites.

${ }^{90}$ Health Insurance Act 1973 (Cth) s 128A.

${ }^{91}$ If the only incorrect detail was the provider number suffix of 2 digits, but otherwise the claim was correct in every particular and the right amount of money was paid correctly for services correctly rendered and the medical practitioner provided additional details on the claim of the service location (which is mandatory data on all modern medical billing software) the authors suggest it would be extremely difficult to mount a compelling prosecution case.

${ }^{92}$ Department of Human Services, eLearning Modules, n 87, Slide 13 of 19.

${ }^{93}$ Telehealth services for medical specialists are included in the Medicare scheme and all that is required is an internet connection and video capability such as Skype. Therefore it is not fanciful for a medical specialist to pull over to the side of the road, power up a laptop (or even just use a mobile phone) and conduct a scheduled, Medicare claimable, online telehealth attendance from a car.
} 
There are many instances in daily practice where medical practitioners may have unknowingly contracted out of their constitutional freedom to set their fees. A common example is the Veterans' Entitlement Act 1986 (Cth) (VEA) which is one of a suite of laws regulating entitlements for exservicemen and women, and current military personnel and their dependants. ${ }^{94}$

The Department of Veterans' Affairs (DVA) has a hybrid role as a publicly funded organisation with diverse portfolios. The $V E A$ deals with what is described as "medical and other treatment" 95 (as opposed to "professional services") with s 90 enabling the preparation of written "Treatment Principles" designed to be legally binding on medical practitioners and articulated in a document called "LMO Notes". ${ }^{96}$

The VEA cross-references the HIA in determining private patient principles ${ }^{97}$ and reflects the constitutional freedom of DVA-eligible patients to enter private arrangements if they wish. DVA has adopted the MBS for its subsidised medical services (though with different fees) and applies Medicare rules. ${ }^{98}$ Since 1985 all DVA claims have been administered by Medicare. ${ }^{99}$ However, the High Court has confirmed that the two schemes are completely separate, French CJ confirming that a medical practitioner unable to participate in the Medicare scheme could continue to provide services to entitled veterans. ${ }^{100}$ Indeed one particular sub-class of entitled veterans who hold injury-specific "white cards" may have no alternative other than to claim through both DVA and Medicare, though separately, in relation to the same visit to a medical practitioner. ${ }^{101}$

Information provided to eligible veterans via its website uses language suggestive of a prohibition against charges being levied by medical practitioners in any circumstances such as:

If you are billed by your LMO / GP or medical specialist, do not pay the account and advise DVA immediately. ${ }^{102}$

Statements such as this suggest that, in similar fashion to Medicare, medical practitioners are assumed to have knowledge of DVA requirements. However, available evidence suggests this is not the case. ${ }^{103}$

When medical practitioners register their provider numbers for electronic claims, they are automatically enrolled in the DVA scheme. ${ }^{104}$ The enrolment process occurs without any active involvement on the part of the medical practitioner, effectively conscripting them into the DVA scheme without their knowledge or consent. Enrolling providers in this way under a false premise of consent may give rise to unintentional non-compliance and create tensions in managing the expectations of patients who have been led to believe all medical services under their DVA entitlements will not incur additional fees. It may also render vulnerable the integrity of the DVA scheme and the ability of the government to

94 Veterans' Entitlement Act 1986 (Cth); Safety, Rehabilitation and Compensation Act 1988 (Cth); Military Rehabilitation and Compensation Act 2004 (Cth).

${ }^{95}$ Veterans' Entitlement Act 1986 (Cth) Pt V.

96 Australian Government, Department of Veteran's Affairs, Providers/Doctors, LMO Notes $<$ https://www.dva.gov.au/providers/doctors\#lmonotes $>$.

${ }^{97}$ Veterans' Entitlement Act 1986 (Cth) s 90A.

98 Australian Government, Department of Veteran's Affairs, Providers/Doctors, Notes for Claiming DVA Fees $<$ http://www.dva.gov.au/sites/default/files/files/providers/fee_schedules.pdfs.

${ }^{99}$ Scotton and Macdonald, n 33.

${ }^{100}$ Wong $v$ Commonwealth (2009) 236 CLR 573; [2009] HCA 3.

${ }^{101}$ For example, a white card holder sees GP for leg injury (which is covered under the white card) as well as the flu, which is not. The claim for the leg must be made under the DVA white card but the claim for the flu cannot be because the flu is not covered under the card. The item 23 for the flu would have to be claimed under Medicare.

102 Australian Government, Department of Veteran's Affairs, Fact Sheets for Eligible Veterans $<$ https://www.dva.gov.au/factsheet-hsv80-local-medical-officer-and-medical-specialist-services $>$.

${ }^{103}$ Faux et al, n 32.

104 Australian Government, Department of Veteran's Affairs, Providers, Becoming a DVA Service Provider $<$ https://www.dva.gov.au/providers/becoming-dva-service-provider $>$. 
prosecute errant medical practitioners who were never afforded an opportunity to know in advance the terms and conditions of the DVA scheme prior to being involuntarily and unknowingly enrolled in it.

Similarly, workers' compensation and third-party claims can present challenges for medical practitioners who may hold an erroneous belief they are not permitted to raise fees against compensable patients beyond the gazetted rates referred to within the various State and Territory schemes. All such schemes derive the majority of services and fees from the MBS, with some additional services being found in the Australian Medical Association (AMA) schedule of fees. ${ }^{105}$ Billing under these arrangements incorporates hybrid Medicare and AMA rules and fees, adding another layer of complexity for medical practitioners who may unknowingly levy incorrect charges in these circumstances. While medical practitioners are expected to know and understand the requirements of each of these schemes, they have no training or skills which would enable them to make a decision about whether they are legally permitted to charge a workers' compensation patient or not. State workers' compensation legislation does not prevail over constitutional provisions and as such, medical practitioners retain an overarching right to charge as they wish. State workers' compensation provisions will typically limit insurer liability, ${ }^{106}$ but this does not have an impact upon a medical practitioner's right to charge a compensable patient as he or she chooses, although it is unlikely a medical practitioner would know this.

\section{Medicare Billing for Hospital Services}

In addition to the basic billing framework presented thus far (that medical practitioners either exercise their constitutional right to set fees as they please, or bill in accordance with other contractual arrangements), when a patient is admitted to an Australian hospital, multiple additional legal layers come into play, with overlapping and sometimes contradictory requirements depending on whether the patient is in a public or private facility.

Options for billing private inpatients under Medicare were expanded in $1998^{107}$ and again in $2000,{ }^{108}$ when changes to the National Health Act 1953 (Cth) and the HIA introduced the ability for patients to assign Medicare benefits to private health insurers (PHIs), the central objective being to simplify billing processes and limit out-of-pocket costs for hospitalised patients. ${ }^{109}$ On the back of a failed attempt by the government to encourage medical practitioners to contract out of their constitutional freedom and fix fee arrangements for in hospital billing, ${ }^{110}$ the Health Legislation Amendment (Gap Cover Schemes) Bill 2000 (Cth) was introduced into Parliament with the objective of controlling medical fees without contracted arrangements. ${ }^{11}$

While referred to as "simplified" billing arrangements, a new medical billing industry quickly emerged to deal with the complexities of the new schemes, under which medical bills involved up to five parties,

\footnotetext{
${ }^{105}$ AMA has maintained its separate schedule of medical fees, which is available only to AMA members or upon payment of a fee $<$ https://ama.com.au/resources/fees-list>.

106 Workers Compensation Act 1987 No 70 (NSW) Pt 3 Div 3 s 61.

107 D Mendelson, "Devaluation of a Constitutional Guarantee: The History of Section 51 (xxiiiA) of the Commonwealth Constitution" (1999) 23 Melb U L Rev 308.

108 Australian Parliament, Bills Digest No. 134 1999-2000 Health Legislation Amendment (Gap Cover Schemes) Bill 2000, (Parliamentary Library, $<$ http://www.aph.gov.au/Parliamentary_Business/Bills_Legislation/bd/Bd9900/2000bd134?print=1>.

${ }^{109}$ See n 108.

${ }^{110}$ Less than 100 medical practitioners across Australia had signed up to the new Medical Purchaser Provider Agreements after two years of operation $<$ https://www.aph.gov.au/Parliamentary_Business/Committees/Senate/Community_Affairs/Completed_inquiries/199699/health/report/c03>.

${ }^{111}$ Then Federal Health Minister Michael Wooldridge said: "This Bill amends the National Health Act 1953 (NHA) and the Health Insurance Act 1973 (HIA) to provide for gap cover schemes. The purpose of these schemes is to enable registered health benefits organisations to provide no gap and/or known gap private health insurance without the need for contracts."
} 
with various contracts and legal relationships that collectively determined the fate of the Medicare rebate at the heart of the transaction. ${ }^{112}$ These schemes, often referred to as "gapcover schemes" remain in common use today. Practically, patients will typically have no involvement in a gapcover transaction though the legal basis for this is somewhat labyrinthine and porous.

Under these schemes, s $20 \mathrm{~A}(2 \mathrm{~A})$ of the HIA provides that an eligible person may enter into an agreement to assign his or her right to the Medicare benefit to a PHI, an approved billing agent or another person. ${ }^{113}$ Such assignment is subject to $\mathrm{s} 20 \mathrm{~B}$, which provides that no signature is required in these circumstances. ${ }^{114}$ The net effect being that a patient may unknowingly enter into an agreement with a PHI allowing the PHI to receive their Medicare benefit but without signing any agreement to that effect.

Where the agreement between the patient and the PHI exists is somewhat a mystery. Available policy documents of some PHIs are silent on the issue but nowhere does there appear to be a specific legal basis facilitating ongoing agreement for all inpatient Medicare benefit entitlements to be automatically assigned to the patient's PHI. This would seem to be quite an important omission.

Further, the wording of s $20 \mathrm{~A}(2 \mathrm{~A})$ refers to a singular "benefit" which is consistent with the overarching provisions of the HIA already discussed. But a question then arises concerning when a patient is admitted to hospital and enters an unsigned agreement with a PHI to assign relevant Medicare benefits, does the PHI have a right to obtain all eligible Medicare benefits under some opaque grouping arrangements or is the PHI subject to the same onerous provisions as medical practitioners who receive assigned Medicare benefits? It would appear the same requirements which may expose a medical practitioner to a risk of criminal liability for each individual professional service claimed do not apply to PHIs, because while medical practitioners are required to obtain the patient's consent every time they provide a service, it appears the PHIs have effectively been given an open and ongoing consent to collect public money, via the patient's Medicare benefit for every inpatient service.

Of further concern is the question of how long the PHI has to transfer Medicare benefits it receives from the government to the medical practitioner. In 1999 s 73AAG(n) and (o) of the National Health Act 1953 (Cth) provided that Medicare benefits must be passed to the medical practitioner within two months. ${ }^{115}$ Further legislative tightening of this provision occurred in 2002. ${ }^{116}$ However, in 2007 the gapcover schemes were completely subsumed into the HIA and the Private Health Insurance Act 2007 (Cth) and provisions relating to a specific timeframe in which the transfer of public money from the health fund to the medical practitioner must take place were removed for PHIs but retained and moved into a new Deed Agreement for approved Billing Agents, who now have 90 days to pass benefits to a medical practitioner. ${ }^{117}$

Following the Peverill decision of the High Court, once a Medicare claim has been received and approved it becomes immediately payable. However, the original intention was that the immediate payment would be made to a provider of professional services (usually a medical practitioner) not a PHI. Billing agents are a further intermediary between the PHI and the medical practitioner who typically

\footnotetext{
${ }^{112}$ Including - a medical practitioner, a patient, the government, the private health insurer and possibly a billing agent.

${ }^{113}$ Health Insurance Act 1973 (Cth), s 20A.

${ }^{114}$ This is because the assignment of benefit takes place under Health Insurance Act 1973 (Cth) s 20A(2A) not subs (1), the latter clause requiring the patient's signature

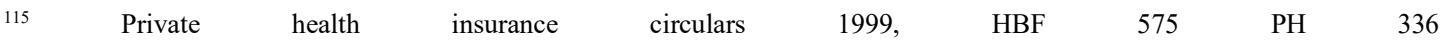

$<$ http://webarchive.nla.gov.au/gov/20100307212147/http://www.health.gov.au/internet/main/publishing.nsf/Content/healthprivatehealth-providers-circulars99-00-575_336.htm>.

${ }^{116}$ By the introduction of the Health Legislation Amendment (Private Health Industry Measures) Act 2002 (Cth). The explanatory memorandum to the Bill stated: "Item 3 amends paragraph (o) of Schedule 1 [of the National Health Act 1953] to insert a reference to sub-section 20A(2AA) of the HIA. This amendment requires health funds to provide the Health Insurance Commission (HIC) with access to documents relating to Medicare benefits paid under a gap cover scheme, when requested to do so by the HIC. This will enable the HIC to access all necessary documents to audit the payment of Medicare benefits and ensure that public money has been properly directed."

${ }^{117}$ Deed Agreement between the Federal Government and a Billing Agent, Clause 9 - Payment to an Assigning Practitioner - $90-$ Day Period $<$ https://www.humanservices.gov.au/sites/default/files/documents/deed-poll.pdf $>$.
} 
manage the billing process for medical practitioners for whom the task is too onerous and complex. Billing agents are often hospitals or medical billing companies who operate trust accounts into which medical billing revenue received from PHIs is paid before being distributed to medical practitioners. This convoluted passage of public money in the form of Medicare benefits processed under gapcover arrangements is shown in Table 3.

Table 3

\begin{tabular}{|c|c|c|c|c|}
\hline Patient -> & Medicare -> & PHI -> & $\begin{array}{r}\text { Billing - } \\
\text { >Agent }\end{array}$ & $\begin{array}{c}\text { Medical } \\
\text { Practitioner }\end{array}$ \\
\hline $\begin{array}{l}\text { Privately insured } \\
\text { patient } \\
\text { unknowingly } \\
\text { agrees to assign } \\
\text { all relevant } \\
\text { Medicare } \\
\text { benefits (MB) } \\
\text { while in hospital } \\
\text { to a PHI. }\end{array}$ & $\begin{array}{l}\text { Applying the High } \\
\text { Court decision in } \\
\text { Peverill, Medicare } \\
\text { must immediately } \\
\text { release payment of the } \\
\text { MB upon receipt and } \\
\text { acceptance of claims. } \\
\text { Accordingly, } \\
\text { Medicare transfers } \\
75 \% \text { of the Medicare } \\
\text { Schedule Fee to the } \\
\text { patient's PHI straight } \\
\text { away. }\end{array}$ & $\begin{array}{l}\text { PHI receives } 75 \% \text { of } \\
\text { the Medicare } \\
\text { Schedule Fee for } \\
\text { each claim and can } \\
\text { retain it indefinitely. } \\
\text { There is no } \\
\text { mechanism or } \\
\text { practical oversite of } \\
\text { the PHIs handling of } \\
\text { this payment of } \\
\text { public money, } \\
\text { particularly oversight } \\
\text { of necessary refunds. }\end{array}$ & $\begin{array}{l}\text { Pursuant to the } \\
\text { terms of the } \\
\text { Deed, a billing } \\
\text { agent must pass } \\
\text { the MB, plus any } \\
\text { additional PHI } \\
\text { component, to the } \\
\text { medical } \\
\text { practitioner } \\
\text { within } 90 \text { days of } \\
\text { receipt from the } \\
\text { PHI. }\end{array}$ & $\begin{array}{l}\text { The medical } \\
\text { practitioner has no } \\
\text { practical control or } \\
\text { visibility over this } \\
\text { entire process and } \\
\text { can be prosecuted } \\
\text { by Medicare } \\
\text { and/or the PHI } \\
\text { acting separately } \\
\text { or together. }\end{array}$ \\
\hline
\end{tabular}

By adding additional parties to the transaction, specifically PHIs (who receive $75 \%$ of the Medicare schedule fee for each inpatient professional service billed), without sufficient regulatory safeguards, the government may have exposed public money to the risk of misappropriation. The most common practical example occurs when PHIs use delaying tactics such as making payment to the medical practitioner contingent upon the happening of another event over which the medical practitioner has no control, such as proof of a corresponding hospital bill for the same service. While relevant contracts between the PHIs, medical practitioners and hospitals may lawfully enable delayed transfer of the PHI component of each payment, the Medicare component should either be immediately released to the medical practitioner or returned to consolidated revenue, which would better serve the national interest. Unfortunately, lax regulation has meant that once the Medicare payment is in the hands of the PHI the government has little practical control over it.

The recent introduction of the Federal Government's new Gold, Silver and Bronze PHI products ${ }^{118}$ may exacerbate gapcover billing challenges because until now, if Medicare approved a claim the PHI was required to also approve and pay it. ${ }^{119}$ However, under the new products this will no longer be the case. All Australians will continue to be eligible for all services under Medicare but no longer under their PHI policies and it is unclear what will happen to Medicare benefits paid to PHIs in circumstances where a patient's PHI policy does not cover a service which Medicare has approved and paid to the PHI. The critical mechanism to return the Medicare benefit to consolidated revenue is unclear.

If a patient disputes a gapcover bill they may direct concerns to all or any of the medical practitioner, the PHI and Medicare, whereas the medical practitioner cannot. The medical practitioner is only able to seek information in relation to a gapcover bill from the PHI, but can be investigated by both Medicare and the PHI, acting separately or together, in relation to a suspect bill. ${ }^{120}$ Furthermore, an unintended

\footnotetext{
118 Private Health Insurance Reforms: Gold/Silver/Bronze/Basic Product Tiers $<$ http://www.health.gov.au/internet/main/publishing.nsf/Content/private-health-insurance-reforms-fact-sheet-gold-gilver-bronzebasic-product-categories>.

${ }^{119}$ Private Health Insurance (Complying Product) Rules 2015 (Cth).

${ }^{120}$ Additionally, medical practitioners can be investigated by the Health Care Complaints Commission and/or the Medical Board of Australia if the patient complains.
} 
consequence of these arrangements is that while bulk billing and charging a gap is a criminal offence as in the case of Sood, ${ }^{121}$ once the same Medicare rebate is passed to a PHI under gapcover arrangements, what was once a criminal offence is effectively reduced to a lesser civil offence where a medical practitioner who generates a gapcover bill but also charges an unauthorised gap may have simply breached a contract term with the PHI.

Gapcover billing has become so complex that even PHIs themselves have been unable to understand it. In 2011 Medibank Private (MBP) (then a government owned PHI) was the last of the major PHIs to commence online gapcover billing. Gapcover legislation provided that patients were to be given written informed financial consent detailing any likely gap payments before they went to hospital. ${ }^{122}$ This provision was inserted to accommodate the hybrid "known gap" schemes where the patient would assign their Medicare benefit to the PHI and also pay another amount to the provider called a "known gap". When MBP commenced online billing, it failed to understand that no gap billing did not, by definition, involve gaps, and proceeded to create a requirement that all no gap bills submitted via its new online billing channel include a declaration that written informed financial consent had been obtained. This caused thousands of correct gapcover bills to be wrongly identified as being incorrect and placed clinicians in the invidious position of having to give a false declaration if they were to have any hope of being correctly paid for legitimate services correctly billed. Some months later MBP conceded its mistake, advising providers that after seeking internal clarity the issue had been rectified and the written consent requirement withdrawn. ${ }^{123}$ It is once again apparent that for the medical practitioners who have to navigate the requirements of these complex schemes there is little support afforded them should they experience confusion and unintentionally err in relation to a bill they submit for payment.

In another recent example MBP appeared to again be unclear about its own complex known gap scheme when it was quoted in the media expressing concern about policy-holders being charged $\$ 500$ gaps which were administered by medical practitioners using split bills, ${ }^{124}$ when this was in fact correct and compliant administration of the very rules MBP had put in place. ${ }^{125}$ Inaccurate reporting such as this has unfortunately become widespread and is a symptom of a bigger problem where the public (including the media) have become so confused about what is and is not compliant medical billing they are prone to believing falsehoods which are difficult for medical practitioners to rebut, particularly when the medical practitioners themselves may be unsure about whether they are billing correctly.

Perhaps the most concerning quite recent addition to the Gordian Knot that has become gapcover regulation is that the terms and conditions of some PHI gapcover schemes ${ }^{126}$ have the effect of making medical practitioner participation in their schemes contingent upon agreement to terms which may place the medical practitioner in breach of the Medicare scheme, in circumstances where the PHIs have questionable jurisdiction to purport to exercise such control. This is explained and presented in Table 4.

\section{Table 4}

\footnotetext{
${ }^{121}$ Sood v The Queen (2006) 201 FLR 119; [2006] NSWCCA 114.

${ }^{122}$ Health Legislation Amendment (Gap Cover Schemes) Act 2000 (Cth), s 73BDD(7).

123 Medibank Private, Informed Financial Consent and Eclipse Claims <http://www.medibank.com.au/HealthCovers/Information-For-Health-Care-Providers/GapCover-Information/Article.aspx?Id=131>.

${ }^{124}$ Patients being bled by specialists as out-of-pocket costs https://www.theaustralian.com.au/nation/health/patients-being-bledby-specialists-as-outofpocket-costs-surge/news-story/04720fe356186190de873461449aead2

125 Medibank Private GapCover Provider Guide <https://www.medibank.com.au/content/dam/retail/providers/gapcover/GapCover-booklet-2018.pdf>.

126 Bupa Medical Gap Scheme Terms and Conditions August 2018 $<$ https://www.bupa.com.au/staticfiles/BupaP3/For\%20Providers\%20Home/MediaFiles/PDF/bup16245-medical-gap-schemeterms-and-conditions.pdf $>$; Terms and Conditions of Using the Medibank GapCover Scheme $<$ https://www.medibank.com.au/content/dam/retail/providers/gap-cover/Revised_Terms_and_Conditions.pdf $>$; NIB Medigap Terms and Conditions < https://www.nib.com.au/docs/medigap-terms-and-conditions $>$.
} 


\section{Medicare Billing in Public Hospitals}

Gapcover schemes are used in both private and public hospitals. In the latter, complex funding arrangements between State and federal governments enable State-run public hospitals to use the additional revenue to supplement annual grant funding. The practical application of these arrangements is to require publicly practising, salaried medical officers, to bill patients who elect to be treated privately. However, some PHIs pay a lesser amount than if the same services were provided in a private hospital, although the legal basis for this is somewhat opaque given the PHIs are required to pay under their Gapcover schemes at the rates approved by the Minister. ${ }^{127}$

Publicly practising medical practitioners are required to bill under their individual Right of Private Practice Agreements (RoPP) for patients who elect to be treated privately. Under these arrangements the hospital will usually retain some or all of the revenue collected. The arrangements are different in every State and Territory as are the arrangements for Visiting Medical Officers (VMO), who may also use gapcover schemes for private patients in public hospitals, though all PHIs will reimburse VMOs at the gapcover rates as opposed to the Medicare schedule fee, representing another anomaly.

Facilitated by provisions of the National Health Reform Agreement (NHRA), ${ }^{128}$ categories of patients in public hospitals were redefined and expanded beyond the two categories used by Medicare which are familiar to medical practitioners, inpatients and outpatients. The NHRA describes patients who are not admitted to a public hospital variously as "non-admitted patients", "outpatients" and "emergency department patients". Emergency department patients, from the medical practitioner perspective, may be thought of as "outpatients" in the sense they have not been formally admitted to the hospital, but such patients cannot legally be billed like other outpatients, although medical practitioners may not understand this. This adds another layer of legal complexity for medical practitioners because, in addition to understanding the provisions of the MBS, workers' compensation and PHI schemes, they are assumed to also have a sound working knowledge of the NHRA and its interface with the HIA, for it is not possible to bill correctly otherwise. ${ }^{129}$ However, the provisions of the NHRA and the MBS sometimes collide ${ }^{130}$ and it can be difficult to apply both correctly across the continuum of patient care in a public hospital setting. ${ }^{131}$

Quite apart from the complexity of gapcover schemes in Australia, the stated policy objective of reducing patient out-of-pocket costs when they go to hospital has failed. ${ }^{132}$ It should be noted that much of this failure is ultimately a consequence of not understanding the practical impact of the CCC on Australian medical billing.

\footnotetext{
${ }^{127}$ The Health Legislation Amendment (Gap Cover Schemes) Act 2000 states the purpose of gapcover schemes is to pay above the Medicare schedule fee and all schemes must be approved by the Minister. It is therefore unclear the legal basis upon which the PHIs limit reimbursement to the Medicare schedule fee for private patients in public hospitals where a gapcover scheme applies.

128 National Health Funding Body (NHFB), National Health Reform Agreement (NHRA), (NHFB, 2011) $<$ https://www.publichospitalfunding.gov.au/national-health-reform/agreement $>$.

${ }^{129}$ For example, a patient presenting to a public hospital emergency department may say to a treating medical practitioner that he/she has private health insurance and is happy to use it. The medical practitioner may then proceed to bill using the patient's PHI gapcover scheme for services provided, even though the NHRA prohibits it unless the patient was admitted.

${ }^{130}$ For example, telehealth services under Medicare can only be provided to outpatients. A medical practitioner may erroneously think emergency department patients are outpatients (because they have not been admitted) and unintentionally claim unlawfully to Medicare for telehealth services.

${ }^{131}$ For example, a rehabilitation physician may incorrectly assume she can bill to Medicare for outpatient case conferences after a public patient has been discharged home but is continuing to return to the public hospital for outpatient follow up. The MBS states: "All care directly related to a public in-patient's care should be provided free of charge. Where a patient has received in-patient treatment in a hospital as a public patient (as defined in Section 3(1) of the Health Insurance Act 1973), routine and non-routine aftercare directly related to that episode of admitted care will be provided free of charge as part of the public hospital service, regardless of where it is provided, on behalf of the state or territory as required by the National Healthcare Agreement. In this case no Medicare benefit is payable."

132 J Doggett, Healthcare's Out-of-Pocket Crisis <https://insidestory.org.au/healthcares-out-of-pocket-crisis/>.
} 


\section{Third-Party Involvement in Medicare Billing}

In some respects Medicare operates like the Australian tax system in that taxpayers are personally responsible for the information they lodge with the Australian Tax Office irrespective of who prepared their tax return. Similarly, medical practitioners are prima facie responsible for every Medicare bill submitted in their name, even though someone else may have prepared and lodged the bill on their behalf. ${ }^{133}$

The impact of third-party conduct in relation to MBS billing is of great significance because in contemporary practice most medical practitioners do not administer their own billing, this being traditionally delegated to office staff and other third parties. Until recently, medical practitioners had sole legal responsibility for medical billing with the exception of cases of criminal fraud. ${ }^{134}$ However, on 1 July $2018 \mathrm{~s} 82$ of the $H I A$ was amended with an expanded definition of inappropriate practice which brought corporate entities within the purview of the Medicare watchdog, the Professional Services Review (PSR), which is discussed below. The purpose of the amendment was to enhance the PSR's ability to review third-party involvement in Medicare billing.

This change to the law recognises that increasing corporatisation of medical practice could potentially be playing a role in the rising incidence of incorrect MBS billing, particularly in circumstances where employed or contracted medical practitioners are contractually bound or incentivised to meet targets or provide certain services to support the financial objectives of the corporate owner. Corporate owners and the Practice Managers they employ, may not necessarily be medically qualified and may have little understanding of Medicare billing requirements, focusing only on the value of each item in the schedule, rather than the important compliance provisions contained in the broader regulatory scheme. ${ }^{135}$

In addition to influence from corporate owners, medical practitioners seek and receive information concerning fees and billing from numerous other third parties one of which is the Australian Medical Association (AMA) which has maintained its own schedule of medical fees for over 40 years. The AMA schedule has its own codes, some of which map to the MBS and some of which do not, and has quasilegal status in that it is the basis for the gazetted rates under many of the various State and Territory workers compensation schemes. ${ }^{136}$ However, inconsistencies between the AMA schedule and the MBS may further contribute to erroneous MBS billing by medical practitioners. ${ }^{137}$

Adding further confusion is a third reference widely used by Australian anaesthetists, who are directed to the ASA Relative Value Guide (RVG) which was developed partly in response to the ambiguity and

\footnotetext{
$133 \quad$ Health Insurance Act $1973 \quad$ (Cth) $\quad$ s $\quad 81 \quad<$ http://www8.austlii.edu.au/cgibin/viewdoc/au/legis/cth/consol_act/hia1973164/s81.html>, defines persons able to be investigated, and describes a list of professionals who have eligibility to claim under the Medicare scheme.
}

${ }^{134}$ Health Insurance Act 1973 (Cth) s 81(2).

${ }^{135}$ For example, a corporate medical practice workflow may provide that all patients attending the practice will each have an electrocardiogram, a cardiac stress test and an echocardiogram before seeing a cardiologist. While efficient operationally, it is arguable that none of these tests, which would draw a total of approximately $\$ 350$ from the public purse, could properly be characterised as clinically relevant, when the patients have not seen a clinician (the cardiologist) prior to having them. This type of inappropriate billing may again be outside of the direct control of the medical practitioner, instead being directed and controlled by corporate business owners and other third parties, though the medical practitioner remains primarily responsible.

${ }^{136}$ The AMA schedule of fees is copyrighted to the AMA is not publically available. It can only be accessed upon the payment of a licence fee for any medical practitioner who wishes to avail it. Services listed in the AMA schedule are a combination of all MBS services, together with additional services which do not correspond to the MBS but which the AMA has deemed as being legitimate, separately chargeable services.

${ }^{137}$ For example, the AMA permits charges to be raised for telephone consultations, whereas the MBS does not. Another example is the AMA is of the view that a separate item for the provision of a steroid injection is available to medical practitioners whereas Medicare disagrees and some years ago removed it from the MBS. However, for medical practitioners who may regularly refer to both schedules in relation to daily billing activity, this may cause an unintentionally fraudulent claim to be raised by a medical practitioner who incorrectly thinks that bulk billing an attendance and also charging separately for a steroid injection is permitted because the AMA suggests it is, whereas under Medicare, such practice would constitute a crime. 
inconsistencies in many of the descriptions of unique anaesthetic services in the MBS. ${ }^{138}$ However, a review of its contents reveals that it may create further confusion for medical practitioners. In some cases, descriptions relating to a single professional service are inconsistent as between the MBS, the AMA Schedule and the RVG. ${ }^{139}$ Yet for Australian anaesthetists who will be held personally responsible should they choose the wrong interpretation, there appears to be nowhere to go to seek reliable advice and support when the three resources provide conflicting information in the context of a billing decision.

Another common third party involved in Medicare billing is public hospital finance departments, because RoPP agreements typically include clauses requiring medical practitioners to appoint the hospital as sole agent for all private Medicare billing as well as giving exclusive use of relevant provider numbers to the hospital to facilitate this activity. Entering into these arrangements is a condition of employment at the hospital, there being usually no option for the medical practitioner to negotiate the specific terms, which effectively hand over the entire administration of billing to hospital staff who themselves may have little knowledge or expertise in this area. Yet the medical practitioner retains personal responsibility for the veracity of submitted bills, though not the income, which is usually retained by the hospital.

More recently, over 20,000 medical practitioners seeking answers to the complexities of medical billing have formed a closed Facebook group in which the founder, a medical practitioner, has self-declared herself as a medical billing expert. ${ }^{140}$ The basis of this declaration appears to be that the medical practitioner has read the MBS and some provisions of the HIA. While commendable, it is somewhat concerning that having never been formally taught how to bill correctly, a medical practitioner is assuming expert status and providing medical billing advice to other medical practitioners under a shroud of secrecy. ${ }^{141}$ However, with nowhere to go to obtain reliable advice and support in relation to Medicare billing it is perhaps not surprising that groups such as this have appeared and that the government currently has no ability to intervene because there is no legal barrier to anyone declaring themselves a medical billing expert and providing education to others on how to extract public money from the Medicare purse. This is inconsistent with other areas of public financing such as taxation where only accountants, tax lawyers and, as a bare minimum, registered tax agents, are permitted to hold themselves out as being experts in the area of taxation.

With no formal education on medical billing occurring throughout their medical training, medical practitioners are vulnerable to adopting direction from numerous third parties who declare themselves experts on the topic of medical billing. This may even extend to financial advisers and accountants, software vendors who may offer prompts or short cuts in the billing process such as predictive billing, as well as practice managers and receptionists who themselves have no formal training in this complex area.

\section{Government Initiatives to Protect the Integrity of Medicare}

\footnotetext{
${ }^{138}$ Anaesthetic services are largely time based, with each unit of time having a dollar value. No other medical specialty in Australia claims in this way. The RVG is available exclusively to members in hardcopy, online PDF and as an App. Currently in its 19th edition, the RVG is heavily relied upon by Australian anaesthetists <https://asa.org.au/wordpress/wpcontent/uploads/Advertising/MediaPack2018RVG.pdf>.

139 MBS item 17615 is an unreferred anaesthetic consultation involving complex assessment and management plan. The corresponding service in the AMA schedule is CA004 which the AMA describes as being equivalent to both of MBS items 17615 and 17645 but does not involve complexity or a management plan. The same service in the ASA (which borrows from both the MBS and the AMA) cross-references the complexity in the MBS but is silent on referrals and management plan. Depending on which source is chosen, an anaesthetist could reasonably interpret the various provisions and claim daily pre-anaesthetic consultations on a post-operative patient without a referral or management plan.

${ }^{140}$ GP Loses Court Challenge on 80/20<https://www.ausdoc.com.au/news/gp-loses-court-challenge-8020-rule> see in particular comments by one doctor who self proclaimed expert status.

${ }^{141}$ Business for Doctors $<\mathrm{https}: / /$ www.facebook.com/businessfordoctors/>.
} 


\section{The Early Days}

Medicare's fee for service payment arrangements rely heavily on the honesty of medical practitioners to claim correctly. Aware of the inherent vulnerabilities of the new national insurance scheme, Medibank's founders established the Medical Services Committee of Inquiry (MSCI) which was charged with the task of monitoring services claimed under the new scheme and investigating possible breaches and referring potential cases of fraud.

By 1992, following an audit by the Australian National Audit Office, the MSCI had been found to be ineffective in deterring incorrect billing by medical practitioners ${ }^{142}$ and was replaced by the PSR Scheme in 1994. The PSR was established as a peer review scheme to examine Medicare services claimed by medical practitioners and to determine whether claiming under the MBS constituted inappropriate practice. The PSR currently reviews between 50 and 100 practitioners annually.

\section{The Introduction and Subsequent Review of the PSR}

The objective of the PSR is to protect the public interest in the standard of Medicare and Pharmaceutical Benefit Scheme services ${ }^{143}$ and, in line with other health regulatory policy (eg practitioner regulation), the sanctions imposed are intended to be remedial rather than punitive. When findings of inappropriate practice are made by the PSR, the penalties imposed are onerous and can include disqualification from participating in the Medicare Scheme.

Unlike other regulated professions, where the names and details of reprimanded or disqualified persons are made public, ${ }^{144}$ PSR decisions are not published, ostensibly to protect the anonymity of errant medical practitioners. Unfortunately, this means that PSR decisions do not contribute to a body of knowledge which might assist medical practitioners to better understand their compliance obligations and prevents the development of doctrinal precedent to inform future decision-making and policy direction. Additionally, the PSR annual reports heavily redact case studies of investigated medical practitioners, making it possible for a medical practitioner to unknowingly learn medical billing from a colleague who has previously been investigated by the PSR.

The lack of transparency of the PSR is particularly concerning when its own annual reports routinely cite practitioner confusion as being a contributing factor in relation to poor MBS compliance. ${ }^{145}$ During his six-year period in the role of PSR Director Tony Webber actively engaged the PSR in Medicare compliance education programs for the profession via face-to-face seminars as well as annual reports to the profession, ${ }^{146}$ both suggestive of an awareness of the prevalence of confusion and a need to address the issue. There is compelling evidence that high levels of confusion regarding correct Medicare billing remain prevalent. ${ }^{147}$

During a 2011 Senate Committee inquiry reviewing the PSR, ${ }^{148}$ submissions from medical practitioners highlighted both the complexity of the Medicare billing system and the inadequacies in the resources available to them concerning its proper use. These submissions directly contradicted submissions from

\footnotetext{
142 Bell, n 27.

${ }^{143}$ Health Insurance Act 1973 (Cth) s 79A.

${ }^{144}$ See legal profession register at this link $<$ http://www.lawlink.nsw.gov.au/olsc/nswdr.nsf/webview $>$ and corporate directors and financial advisors at this link $<\mathrm{https} / /$ asic.gov.au/online-services/search-asics-registers/banned-and-disqualified/>.

145 Commonwealth Department of Health, Professional Services Review, Annual Report (2008-2009) (Commonwealth of Australia, 2009) <https://www.psr.gov.au/sites/default/files/PSR_Annual_Report_2008-09.PDF?v=1478693046>.

146 Australian Government, Professional Services Review Other Publications (Web page, 2019) $<$ http://www.psr.gov.au/publications-and-resources/other-publications $>$.

${ }^{147}$ See 140 , see the 161 comments left by readers which demonstrate widespread confusion and one Doctor demonstrated a failure to understand the operation of the CCC.

${ }^{148}$ Commonwealth of Australia, Community Affairs References Committee, Review of the Professional Services Review (PSR) Scheme, October 2011.
} 
Medicare which suggested that ample resources and reliable support were available. ${ }^{149}$ One submission indicated that processes should be in place to enable clinicians to obtain clarity about the use of the MBS and another drew a comparison between the advice and written rulings available from the Australian Taxation Office (ATO) and the lack of such information and advice from Medicare, suggesting that this meant medical practitioners could unknowingly fall into non-compliance. ${ }^{150}$ The Senate Committee resolved that a "watching brief" should be kept to ensure that optimal educational material and information should always be available to practitioners though fell short of detailing who should fulfil this obligation. ${ }^{151}$ It appears that informal, ad hoc training and advice from unqualified individuals, such as the closed Facebook group already mentioned, have attempted to fill this void.

Of major concern is a recent, unprecedented decision taken by the PSR in which it dismissed written advice from Medicare, which had been provided to a medical practitioner concerning the billing of a particular service. In its deliberations the PSR stated that Medicare's advice was incorrect ${ }^{152}$ and in so doing, undermined the government as being the authority for correct Medicare billing advice. This decision may have effectively closed off the only remaining legitimate avenue of advice and support which medical practitioners might reasonably have expected to rely upon for medical billing decisions.

\section{Government Audits}

In addition to the PSR, as part of the Increased Medicare Compliance Audit Initiative (IMCA), new legislation was enacted in 2011 which enhanced Medicare's audit capabilities. ${ }^{153}$

Activity under the new Act commenced in 2012. ${ }^{154}$ However, a 2014 report by the Auditor General indicated that Medicare's compliance initiatives since 2008 had been largely unsuccessful. ${ }^{155}$ The report acknowledged the complexity of Medicare billing, ${ }^{156}$ highlighting the need for appropriately skilled departmental staff to undertake compliance audit work because the ability to correctly detect inaccurate claims requires prerequisite knowledge of accurate claims. However, the auditor found that rather than compliance management relying on specific policies or guidelines, the internal operating environment of the department consisted largely of unwritten "common knowledge", ${ }^{157}$ inconsistency in approaches taken and interpretation of service requirements by audit staff, ${ }^{158}$ accurate claims being falsely recorded as inaccurate, ${ }^{159}$ Medicare debts being inaccurately calculated ${ }^{160}$ and inappropriate reliance on "local

\footnotetext{
${ }^{149}$ Commonwealth of Australia, Community Affairs References Committee, n 148.

${ }^{150}$ Commonwealth of Australia, Community Affairs References Committee, n 148.

${ }^{151}$ Commonwealth of Australia, Community Affairs References Committee, n 148.

${ }^{152}$ In Nithianantha $v$ Commonwealth of Australia [2018] FCA 2063, [193], the PSR Committee rejected written advice from the Provider Services Branch of the Department of Human Services that had been submitted in evidence, saying the advice was "not correct". The medical practitioner had attempted to rely on the written advice to justify a medical billing decision but was unsuccessful, because the PSR Committee effectively said the advice from Medicare was wrong.

${ }^{153}$ Health Insurance Amendment (Compliance) Act 2011 (Cth). In her second reading speech on 17 November 2010, then Health Minister Nicola Roxon said: "On average, 20 per cent of practitioners contacted by Medicare Australia do not respond to, or refuse to cooperate with, a request to substantiate a Medicare benefit paid for a service. When this occurs, Medicare Australia does not have any authority to require a practitioner to comply with the request. This means that there is no way to confirm that the Medicare benefit is correct. This legislation is intended to address that deficiency."

154 Medicare Annual Report 2011-2012 <https://www.humanservices.gov.au/organisations/about-us/annual-reports/annualreport-2011-12>.

${ }^{155}$ Commonwealth of Australia 2014, Australian National Audit Office, Medicare Compliance Audits, Department of Human Services, Audit Report No 26 2013-2014.

${ }^{156}$ Commonwealth of Australia 2014, Australian National Audit Office, n 155.

${ }^{157}$ Commonwealth of Australia 2014, Australian National Audit Office, n 155.

${ }^{158}$ Commonwealth of Australia 2014, Australian National Audit Office, n 155.

${ }^{159}$ Commonwealth of Australia 2014, Australian National Audit Office, n 155.

${ }^{160}$ Commonwealth of Australia 2014, Australian National Audit Office, n 155.
} 
knowledge and experience"161 (rather than written, robust internal education programs) all of which was "expected to be addressed largely through on-the-job training". ${ }^{162}$ It is worth noting that institutional protection of this nature suggests a possibly pervasive view within the department that medical practitioners have a higher level of legal literacy in regard to correct use of Medicare than Medicare's own staff, who themselves may sometimes not understand the requirements of the scheme, have no background or experience in health, and are not subject to penalties if their conduct is non-compliant.

\section{Education Initiatives}

In 1985, one year after the revived Medibank scheme (renamed Medicare) was introduced, educating medical practitioners was again reported as an effective strategy in promoting voluntary compliance. ${ }^{163}$ This was echoed in the Auditor General's report 30 years later in his general acknowledgment that the department's education initiatives were central to overall maintenance of system integrity.

Further evidence of the importance of medical practitioner education for improving billing compliance was seen in 2007, when the then Minister for Human Services announced education as being the key to compliance stating that $\$ 250$ million in program savings had been achieved in the previous year through education initiatives which had changed the claiming patterns of practitioners. ${ }^{164}$ Although the Department repeatedly states that education is critical in managing billing compliance prospectively, ${ }^{165}$ education initiatives have been generally short-lived, and a recent Australian study found that Australian medical practitioners do not now, and have never received formal education on correct billing under Medicare. ${ }^{166}$

\section{Decreasing Administrative Support}

Despite the combination of greater complexity, increased scope and the substantial growth in the number of available medical services and MBS claiming activity over the last 40 years, the administrative and support infrastructure of Medicare has declined considerably since its inception. The success of Medibank was dependent on the ability of the federal government to prove it could successfully process millions of claims from day 1. A dedicated team was established in the Health Insurance Commission (HIC) for this purpose. ${ }^{167}$ The decision to create a separate commission was significant for two reasons. The first was to protect the Medibank levy from political whim, ${ }^{168}$ and the second was a critically important structural component designed to establish and retain departmental expertise. HIC staff were employed outside of the Public Service Act 1999 (Cth), ensuring long-term retention of essential expert

\footnotetext{
${ }^{161}$ Commonwealth of Australia 2014, Australian National Audit Office, n 155.

${ }^{162}$ Commonwealth of Australia 2014, Australian National Audit Office, n 155.

${ }^{163}$ K Flynn. Medical Fraud and Inappropriate Practice in Medibank and Medicare, Australia 1975-1995. Doctor of Philosophy thesis, School of Social Sciences, Media and Communications, University of Wollongong (2004) 270 $<$ http://ro.uow.edu.au/theses/2071/>.

${ }^{164} \mathrm{https}$ ://www.humanservices.gov.au/organisations/about-us/annual-reports/archive/annual-reports-2006-2007 .

${ }_{165}$ Senate Standing Committee on Community Affairs, Parliament of Australia, Inquiry into Compliance Audits on Medicare Benefits (Final Report, June 2009) $<$ https://www.aph.gov.au/parliamentary_business/committees/senate/community_affairs/completed_inquiries/2008-

10/medicare_benefits_compliance_audits/report/c01>.

${ }^{166}$ Faux et al, n 32.

${ }^{167}$ Human Services (Medicare) Act 1973 (Cth).

${ }^{168}$ Boxall and Gillespie, n 8: "[T] $]$ he independence of the commission was closely associated with the idea of insulating the determination of the health insurance levy rate from short term political decisions."
} 
knowledge. ${ }^{169}$ By establishing a dedicated authority comprising staff who were employed outside of the public service, it was predicted that expertise would not be lost with every round of promotions. ${ }^{170}$

However, in 2005 the Health Insurance Commission Act 1973 (Cth) was renamed the Medicare Australia Act 1973 (Cth) and included reforms that dissolved the HIC as a separate commission and established it as an agency of the Department of Human Services. This had a twofold effect: it facilitated increased ministerial control over the new agency; and it made all HIC staff employees of Medicare Australia under the Public Service Act. The original safeguards, specifically designed to retain departmental Medicare expertise, were permanently undone from the moment HIC employees became employees under the Public Service Act, because there were no longer any barriers to prevent Medicare staff from moving to other departments within the public service.

In a further dilution of expertise, in 2011, the largest overhaul in public service history was facilitated by legislative change which renamed the Medicare Australia Act 1973 (Cth) as the Human Services (Medicare) Act 1973 (Cth) and enabled the Department of Human Services to became a single state department integrating Centrelink, Medicare, the Child Support Agency and CRS Australia.

As a result, the necessary infrastructure to support the operation of Medicare (the fourth largest expenditure item in the federal budget) ${ }^{171}$ is now so inadequate that neither compliance nor reform can be properly managed.

\section{The MBS Review Taskforce}

Medicare's founders anticipated the need for ongoing review and management of subsidised services in the scheme, and established the Medicare Benefits Advisory Committee (MBAC) for this purpose. The functions of the MBAC are set out in Pt V of the $H I A^{172}$ and include considering the manner and the extent to which a particular service should be included in the Medicare scheme, including applicable fees. Composition of the MBAC describes a quorum of five, three of whom must be medical practitioners. ${ }^{173}$ Of note, the role of the MBAC excludes making recommendations beyond clinical matters and fees. The committee operates at the professional service level and is not permitted to propose changes to the underlying legal structure.

This notwithstanding, in 2015 the Federal Government established a new body, called the MBS Review Taskforce (MBSRT). The stated purpose of the MBSRT is to align Medicare-funded services with contemporary clinical evidence ${ }^{174}$ and the work of the taskforce is nearing completion. The MBAC describes a point of differentiation between it and the MBSRT on its website stating its work is mostly prospective (assessing applications for new services to be included in the MBS) while the work of the MBSRT is largely retrospective, ${ }^{175}$ although there appears to be some degree of overlap and duplication. The MBSRT terms of reference also permitted it to review the underlying legal structure and billing rules. ${ }^{176}$

\footnotetext{
${ }^{169}$ Boxall and Gillespie, $\mathrm{n} 8$ : "The ethos of the public service was that you get a job, and as soon as you get a job, you start looking through the notices and finding something one level above you."

${ }^{170}$ Boxall and Gillespie, $\mathrm{n} 8$ : "[P]romotional opportunities lay within the Commission so you build up a core of expertise .... they didn't lose people. People spent their entire careers within the HIC."

${ }^{171}$ Australian National Audit Office, n 23.

${ }^{172}$ Health Insurance Act 1973 (Cth) s 67.

${ }^{173}$ Health Insurance Act 1973 (Cth) s 75.

${ }^{174}$ Australian Government, Department of Health, Terms of reference - Medicare Benefits Schedule Review Taskforce (Web page, 2016-2017) <http://www.health.gov.au/internet/main/publishing.nsf/content/MBSR-tor>.

${ }^{175}$ Australian Government, Department of Health, Medical Services Advisory Committee (MSAC) Frequently Asked Questions (Web page 2019) <http://www.msac.gov.au/internet/msac/publishing.nsf/Content/FAQ-01>.

${ }^{176}$ Australian Government, Department of Health, n 174.
} 
On 1 November 2017, the government accepted sweeping changes to the MBS based on recommendations of the MBSRT which may have further obfuscated some of the already opaque legal principles discussed in this article. Specifically, rather than referring to the key tenets of clinical relevance and necessity, the MBSRT introduced a new concept, that of "reasonableness", ${ }^{177}$ stating that it was reasonable for two common services to be billed together only if the higher paying service had a value under $\$ 300$ but not if it had a value over $\$ 300$. An unintended consequence of introducing reasonableness as a standard is that clinical relevance has effectively been undermined and avenues for the government to prosecute breaches of the scheme may have been further eroded. ${ }^{178}$ While the response of medical practitioners affected by this change is unknown, it would be a pyrrhic victory for the government if this somewhat arbitrary $\$ 300$ cap has been shifted to consumers in the form of higher outof-pocket costs or medical practitioners having simply adjusted their billing patterns to maintain their incomes.

Further, for medical practitioners who are required to navigate Medicare's changing rules, there is no clarity around the way the PHIs should apply such rules in a gapcover context. Medicare benefits make up approximately half or more of every claim made under a gapcover bill and with no interpretation of how such a change is to be applied in that context, there is nothing to prevent a PHI rejecting a claim for an attendance and a procedure claimed together when the procedure has a Medicare schedule fee of $\$ 250$, on the basis that once the PHI component is added, the total amount payable is over $\$ 300$. Despite the fact this may not be the intention, there is no practical ability for a medical practitioner to dispute such action. Further, the medical practitioner may unintentionally breach PHI scheme requirements unknowingly due to the arbitrary and inconsistent application of new Medicare rules by the PHIs.

It is widely accepted that the MBSRT has done good work in revising clinical descriptions of professional services, many of which have not been reviewed for decades. However, there has been less support when the MBSRT has ventured into the underlying legal structure and law reform. In a recent example, the MBSRT proposed that a certain category of medical practitioners be prevented from billing independently. ${ }^{179}$ The response from industry was swift and brutal, and while the arguments put by industry responders (who included medical practitioners) were correct in pointing out the serious practical consequences of the proposed changes, ${ }^{180}$ of more concern was an apparent failure to

\footnotetext{
177 The new rule provides that claiming an attendance item is not "reasonable" if the associated procedure being claimed on the same occasion of service has a value equal to or greater than $\$ 300$. However procedures under $\$ 300$ are not affected because it is "reasonable" to claim both an attendance and a cheaper procedure, one of the stated reasonings being to protect General Practitioners.

178 Australian Government, Department of Health, Addressing variations in billing of medical consultations (Web page 2019) $<$ http://www.health.gov.au/internet/main/publishing.nsf/Content/MBSR-addressing-variations-in-billing-of-medicalconsultations $>$. The same attendance item cannot be clinically relevant for associated services with a value under $\$ 300$ (with no questions asked), but not clinically relevant with procedures over $\$ 300$. Following the reasoning in Dr Sood's case, the prosecution case would surely now fail as demonstrated in the following hypothetical example: Dr X bulk bills colonoscopy item 32088 with a schedule fee of $\$ 334.35$ and is now prevented from also billing attendance item 116 which has a value of $\$ 75.50$. Dr X decides to charge the patient separately, in similar fashion to Dr Sood, a fee of $\$ 100$ for the attendance, which the patient pays in cash and cannot claim. If one follows the reasoning in Sood, the attendance is inextricably linked to the procedure, cannot be billed separately under the Health Insurance Act 1973 (Cth) s 20A, and may give rise to criminal liability. However, it would no longer be possible to succeed with the prosecution argument in Sood's case because the same attendance items are clearly separate in the schedule for other colonoscopy services such as item 32087 which has a fee of $\$ 204.70$. One can no longer argue that all colonoscopies include an attendance component when those under $\$ 300$ do not, but those over do.

${ }^{179}$ Michael Grigg, Medicare Benefits Schedule (MBS) Review-Proposed changes to remuneration arrangements for surgical assistants (Medicare $\quad$ Benefits Review Taskforce, $<$ https://gallery.mailchimp.com/42742fbf9182f90c3f06a123c/files/91c9b261-9e76-48f2-bc59-

d6f835689f3d/MBS_Review_Taskforce_Consultation_Surgical_Assistants_letter_to_stakeho..._1.pdf $>$.

180 Response from the AMA $<$ https://ama.com.au/system/tdf/documents/Bartone $\% 20$ to\%20Grigg\%20re\%20changes $\% 20$ to\%20remuneration $\% 20$ arrangemen ts\%20for\%20surgical\%20assistants.pdf?file=1\&type=node\&id=49361> response from the RACGP $<$ https://www1.racgp.org.au/newsgp/professional/racgp-rejects-proposed-cuts-to-surgical-assistance> response from the Medical Surgical Assistants Society of Australia <https:/gallery.mailchimp.com/42742fbf9182f90c3f06a123c/files/01a0fe4e-ef0d-4bb6-
} 
understand very basic structural elements of the regulatory scheme including the contractual nature of the relationship between a doctor and patient. Further it was apparent that the operation of the CCC had not been considered or understood because the proposed changes had the potential to expose the government to a High Court challenge based on a practical compulsion argument in breach of the CCC.

\section{CONCLUSION}

Medical billing in Australia has become so convoluted that we are beginning to see signs of the Medicare system unravelling. Lax regulation and constant tinkering at the system's periphery has led to Medicare being more vulnerable to abuse and non-compliance than 40 years ago.

Exacerbating the government's current challenges are the increasing numbers of organisations selfdeclaring as experts who are providing education to medical practitioners on everything from "maximising Medicare" to how to "pack and stack" Medicare item numbers. ${ }^{181}$ In addition, one medical practitioner has successfully crowd-funded an ongoing legal action against the government seeking declaratory relief against the PSR for procedural unfairness and a denial of natural justice. ${ }^{182}$ The authors of an article published in the Medical Journal of Australia specifically cited compliance with Medicare rules as being a contributing factor to medical practitioner burnout and suicide. ${ }^{183}$

The rapid pace of relentless change to services and billing rules proposed by the MBSRT and implemented by the government is not only inconsistent with international best practice standards, ${ }^{184}$ but is also arguably rendering the Medicare scheme more vulnerable to abuse than ever before. The government has little ability to deal effectively with this because it has become almost impossible for medical practitioners to have certainty that they are using the Medicare scheme correctly from one day to the next. A service successfully billed and paid one day may be rejected the next due to a rule change the medical practitioner was unaware of and there is nowhere for the medical practitioner to go to obtain reliable advice and support. Yet medical practitioners are expected to know every nuance of the labyrinthine and constantly changing Medicare billing rules that they were never taught. ${ }^{185}$

Constant changes are also having unintended downstream negative consequences through the PHI legislation, workers' compensation and other third-party payer schemes, the Veterans' Affairs legislation, all the way through to the complex payment arrangements and coding systems that deliver funding to Australian hospitals. The ultimate point of impact occurs when a service has been provided and a bill is required to be settled between a medical practitioner and a patient. This impact is increasingly taking the form of out-of-pocket costs, in a context where Australian consumers, who ultimately fund both Medicare and the PHI industry, have no ability to understand or question why they are paying again, when they have already paid via their taxes and PHI contributions.

Fifty years after the Nimmo report, the operation of our health payment arrangements has again become unnecessarily complex and beyond the comprehension of many. The levels of trust between medical practitioners, PHIs, Medicare, hospitals and patients, in relation to health financing transactions are at a record low, and there are no policy solutions in sight. While we continue to run up a down escalator in the area of meaningful health reform, ignoring structural weaknesses, the demand for health services

a1f8-6b2e21c52f86/MSAS letter to the colleges.pdf> and response from an affected Cardio-thoracic surgeon

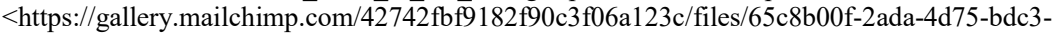

57d24d84b707/Letter_to_Prof_Michael_Grigg.pdf>.

${ }^{181}$ Business for Doctors, n 141; Medical Billing Experts, <https://www.medicalbillingservices.com.au/>.

${ }^{182}$ PSR legal challenge gathers momentum $<$ http://medicalrepublic.com.au/psr-legal-challenge-gathers-momentum/18099>.

${ }^{183}$ M Baigent and R Baigent, "Burnout in the Medical Profession: Not a Rite of Passage” (2018) 208(11) Med J Aust 471.

${ }^{184}$ In all other countries medical payment and coding systems are updated no more than once per annum to enable all affected stakeholders including hospitals, medical practitioners, software vendors and others to make necessary changes to their systems and processes to be ready for new items and fees to commence on a set date. For example see: US transition to ICD 10 $<$ https://www.cdc.gov/nchs/icd/icd10cm_pcs_faq.htm $>$ and annual French system update for 2019 $<$ https://www.atih.sante.fr/sites/default/files/public/content/3502/cim-10_2019.pdf $>$.

${ }^{185}$ Faux et al, n 32. 
will continue apace, out-of-pocket costs will inevitably continue to rise as medical practitioners and hospitals circumvent reimbursement barriers and demand up-front payment, private health insurance coverage is likely to continue to fall as a result (perceived as poor value by consumers) and the efficient, responsive and equitable modernisation of our excellent health system will remain elusive. For the medical practitioners required to navigate the increasing complexity, they will remain at risk of investigation and prosecution working in a system they cannot avoid, but do not understand. 